\title{
The tensile creep behavior of SiC-based fibers with low oxygen content
}

\author{
Cédric Sauder ${ }^{\mathrm{a}, \mathrm{b}}$ and Jacques Lamon ${ }^{\mathrm{a}}$
}

${ }^{a}$ Laboratoire des Composites Thermostructuraux, UMR 5801 : CNRS - Snecma - CEA - UB1, 3 Allée de la Boétie, 33600 Pessac, France, e-mail : lamon@lcts.u-bordeaux1.fr sauder@,1cts.u-bordeaux1.fr

${ }^{\mathrm{b} C o m m i s s a r i a t ~ a ̀ ~ l ' e ́ n e r g i e ~ a t o m i q u e, ~ D E C / S P U A / L M P C, ~} 13108$ Saint Paul les Durance, France, e-mail : sauder@lcts.u-bordeaux1.fr, cedric.sauder@cea.fr.

\begin{abstract}
The creep behavior of Hi-Nicalon, Hi-Nicalon S and Tyranno SA3 fibers is investigated at temperatures up to $1700^{\circ} \mathrm{C}$. Tensile tests were carried out on a high capability fiber testing apparatus in which the fiber is heated uniformly under vacuum. Analysis of initial microstructure and composition of fibers was performed using various techniques. All the fibers experienced a steady-state creep. Primary creep was found to be more or less significant depending on fiber microstructure. Steady-state creep was shown to result from grain boundary sliding. Activation energy and stress exponents were determined. Creep mechanisms are discussed on the basis of activation energy and stress exponent data. Finally, tertiary creep was observed at very high temperatures. Tertiary creep was related to volatilization of SiC. Results are discussed with respect to fiber microstructure.
\end{abstract}

\section{1- Introduction}

$\mathrm{SiC} / \mathrm{SiC}$ composites are designed to be used at high temperatures in various systems including aerojet engines and stationary gas turbines for electrical power/steam cogeneration on the one hand. Furthermore, owing to the stability of $\mathrm{SiC}$ under neutron irradiation and to recent progress in the fabrication of stoechiometric fibers, it is considered that $\mathrm{SiC} / \mathrm{SiC}$ composites 
are possible candidates for nuclear applications, such as, for instance, structural components facing the plasma in fusion reactor ${ }^{1,2}$, or control bars and fuel containers in the Generation IV nuclear power plants.

Structural performances of $\mathrm{SiC} / \mathrm{SiC}$ composites depend on fiber reinforcement, and more particularly on sensitivity of mechanical properties of fibers to temperature and environment. The present paper focuses on the creep behaviour of SiC-based fibers with a low oxygen content under inert atmosphere. These fibers are potential candidates to reinforcement of $\mathrm{SiC} / \mathrm{SiC}$ composites for nuclear applications.

A lot of papers on the creep behaviour of ceramic fibers are available in the literature. Data have been produced on $\mathrm{SiC}$-based fibers ${ }^{\text {see for instance }}{ }^{3-8}$. Authors used mainly uniaxial tensile loading conditions, or a qualitative technique such as BSR (Bending Stress Relaxation). But only some of these papers were interested in the creep mechanisms ${ }^{4,6,8}$.

Testing tiny objects such as small diameter ceramic fibers (diameter may be as small as 10 $\mu \mathrm{m})$ at high temperatures for long times is not straightforward. Results and analyses may be biased as a result of testing conditions. Testing method thus warrants consideration in order to produce valuable results.

During most of the tensile creep tests reported in the literature, the fiber was not at a uniform temperature (cold gripping method). Furthermore, test duration rarely exceeds 48 hours, for practical reasons associated to the design of experimental set up. 
The cold grip based technique presents a few important drawbacks. Fiber specimens are generally quite long (length averages $100 \mathrm{~mm}$ ), and there is a significant temperature gradient. Owing to temperature gradient, determination of creep strain from fiber deformation is not straightforward $^{9}$. Heavy and tedious calibration operations are required. Then, the use of long specimens is not recommended because of fiber diameter variation. Specimen length must be selected with respect to wave length in diameter variation ${ }^{10}$.

In the hot grip based technique, short specimens are used and the entire fiber can be at a uniform temperature. Some authors claim that fiber may degrade due to the cement used for gripping fiber ends. This difficulty can be overcome with recent products. Furthermore, results obtained using the hot grip based technique appeared to be consistent with other available data ${ }^{3}$.

Thus, in the present paper, some effort was directed toward the testing method, in order to overcome the difficulties associated to the cold grip based technique, and to produce valuable creep data on the last generation of SiC-based fibers.

\section{2- $\quad$ Fibers and experimental procedure}

\section{1- Description of fibers}

Hi-Nicalon and Hi-Nicalon S (Nippon Carbon Co) and Tyranno SA3 (Ube Indstry ltd.) SiCbased fibers were investigated (Table 1). Two different batches of Tyranno SA3 fibers were tested (they are referred to as SA3 (1) and SA3 (2)). Sylramic fibers were not considered in this study because they contain boron, which makes them sensitive to significant degradation under neutron irradiation ${ }^{11}$. 
Quantitative analyses of fibers composition and structure were performed using X-Ray Diffraction, Raman Spectroscopy, Transmission Electron Microscopy (TEM), Electron Probe Microanalysis (EPMA) and fractography. Specimens for TEM were prepared following the method proposed by Berger and Bunsell ${ }^{12}$.

\section{2- Creep tests}

The fiber samples were taken from tows (gauge length $25 \mathrm{~mm}$ ). Graphite grips were affixed to sample ends using carbon based cement C34 (from UCAR Co).

The creep tests were performed on a tensile device (figure 1) designed for testing carbon fibers at temperatures up to $3000^{\circ} \mathrm{C}^{13}$. Heating is generated by electric current circulating through fiber, under secondary vacuum (residual pressure $\sim 10^{-4} \mathrm{~Pa}$ ). Under such environment, active oxidation is infinitively slow ${ }^{14}$. Temperature of fiber was measured using a bichromatic pyrometer. Temperature profiles showed that temperature is uniform over more than $95 \%$ gauge length ${ }^{13}$. Furthermore, it appeared that grips remained at a temperature close to room temperature during the tests $\left(<50^{\circ} \mathrm{C}\right)$. Thus, the loading frame compliance was not affected during the tests. Fiber deformations can be derived from grip displacement. Loading frame compliance was taken to be equal to that estimated at room temperature. Computations of temperature distributions for various thermal conductivities showed that the temperature gradient from the core to the surface of the fiber is less than $2^{\circ} \mathrm{C}$ at $1000^{\circ} \mathrm{C}^{13}$.

Fiber was first kept stress free at the test temperature for $30 \mathrm{mn}$. Then the stress was applied. This operation took less than 10 seconds. Diameter of each fiber was measured in-situ using a laser mounted on the testing apparatus. It is given by the average of several measurements 
along the gauge length. To ensure a good reproducibility of results, only those specimens with quite uniform diameters were tested. For these specimens, diameters measured along fiber differed from the average by less than $3 \%$.

Fiber deformations were derived from grip displacement. Data were corrected to account for deformation of loading frame. The loading frame compliance was estimated using the conventional calibration technique based on tensile tests on fibers having various gauge lengths ${ }^{15}$. As indicated above, since the grips remained at a temperature close to room temperature during the tests, the loading frame compliance estimated at room temperature was pertinent.

Most of the creep tests were interrupted before fiber failure, for analysis of crept fibers. Stresses in the range 150-850 $\mathrm{MPa}$ were applied, whereas temperatures were in the 1150 $1700^{\circ} \mathrm{C}$ range. Tests as long as 350 hours, were performed in order to identify the different creep stages.

\section{3- $\quad$ Results and discussion}

\section{1- Structure and composition of fibers}

Table 1 summarizes results of microstructural analyses. All the fibers contain a small amount of oxygen $(0.2 \%)$. Higher oxygen contents were reported for Hi-Nicalon fibers ${ }^{6,16}(0.6-0.9$ w/o).

There is a larger amount of free carbon in the Hi-Nicalon fiber when comparing with HiNicalon S. Hi-Nicalon S is stoechiometric, but results indicate an excess of carbon. Figures 
2(a) and 2(b) show that element concentration is uniform in both fibers. However, a carbon rich phase was detected using EPMA. It was located in the surface, over a thickness $<100$ nm.

Hi-Nicalon fiber microstructure is well documented ${ }^{6,17,18}$. Thus, data from the literature can be reported here. Hi-Nicalon fibers consist of fine $\beta-\mathrm{SiC}$ grains, that may be faulted ${ }^{18}$. Grain size averaged $5 \mathrm{~nm}$ (table 1). The largest grains were $20 \mathrm{~nm}$ (table 1). The carbon phase (turbostratic carbon) consists of distorted stacks of 5-10 graphitic planes, 2 to $5 \mathrm{~nm}$ long.

Hi-Nicalon $\mathrm{S}$ is made up of clusters of $\mathrm{SiC}$ grains (figure 3). Grain size averages $20 \mathrm{~nm}$ (table 1). The biggest grains were $50 \mathrm{~nm}$ large. Carbon is located between the $\mathrm{SiC}$ grains (figure 4). Grains boundaries do not appear clearly (figure 4).

Concentration in $\mathrm{C}$ and $\mathrm{Si}$ was not found uniform in the SA3 fibers (figure 2). There is a larger amount of free carbon present in the core. The SA3 (1) fiber contained a larger amount of free carbon when compared to more recent SA3 (2) (table 1). Elemental composition in SA3 (2) is closer to stoechiometry, suggesting that fibers of this second batch have been improved. A carbon rich phase was detected in the surface, over $300 \mathrm{~nm}$ in the SA3 (1) fibers and $100 \mathrm{~nm}$ in the SA3 (2) ones. Aluminum was identified (table 1). According to Ishikawa ${ }^{19}$, Al aggregates at grain boundaries.

Grain size is much larger when comparing with Hi-Nicalon and Hi-Nicalon S fibers. Difference in grain size can be noted from micrographs shown on figure 5 . The size of $\beta-\mathrm{SiC}$ grains averaged $200 \mathrm{~nm}$ (table 1). The biggest grains were $400 \mathrm{~nm}$ large. Grains displayed stack faults (figure 3). This explains the discrepancy in grain sizes estimated using XRD and 
TEM (table 1). Grain size was bigger from the core to the surface of fibers. As opposed to HiNicalon S fibers, grain boundaries are clearly marked (figure 4). Carbon shows a turbostratic structure. It is located between $\beta-\mathrm{SiC}$ grains (figure 4).

\section{2- Creep behaviour}

The typical creep curves that were obtained are shown on figure 6. Steady state creep was observed after a more or less long primary creep stage, depending on fiber : after about $140 \mathrm{~h}$ for Hi-Nicalon fibers at $1200^{\circ} \mathrm{C}$, about 72 hours for SA3 (1) fiber at $1200^{\circ} \mathrm{C}$, about 8 hours for SA3(2) fiber at $1250^{\circ} \mathrm{C}$, and about 8 hours for Hi-Nicalon $\mathrm{S}$ at $1350^{\circ} \mathrm{C}$. The creep results reported by most authors were obtained during much shorter tests ( $<48$ hours). Thus, it may be anticipated that their tests were not sufficiently long, so that true secondary creep stage was probably not reached.

Figure 7 shows a typical creep curve obtained under incremental temperature steps. It can be noted that creep accelerated at temperatures $>1600^{\circ} \mathrm{C}$ (tertiary creep). Creep curves were fitted by the following well accepted equations of deformations in the primary and in the secondary stages. Tertiary creep is examined in a subsequent section :

$$
\begin{aligned}
& \varepsilon_{\mathrm{e}}=\frac{\sigma}{E_{o}} \\
& \varepsilon_{\mathrm{p}}=\sigma \mathrm{A}[1-\exp (-\mathrm{pt})] \\
& \varepsilon_{\mathrm{s}}=\mathrm{B} \sigma^{\mathrm{n}} \mathrm{t} \\
& \varepsilon=\varepsilon_{\mathrm{e}}+\varepsilon_{\mathrm{p}}+\varepsilon_{\mathrm{s}}
\end{aligned}
$$


where subscripts, e, p and s refer respectively to elastic regime, primary and secondary creep. $\sigma$ is the stress on fiber, $E_{o}$ is initial fiber Young's modulus, $t$ is time, $A, B, n$ and $p$ are constants.

Figure 6 shows that an excellent agreement was obtained for quite all the fibers. Note that HiNicalon S and SA3 fibers are less sensitive to creep than Hi-Nicalon.

Based on microstructure analysis, the fibers can be considered to be a mixture of wrinkled carbon-layer packets and $\mathrm{SiC}$ grains. Possible controlling creep mechanism may involve grain boundary sliding, carbon diffusion, dewrinkling, deformation and sliding of carbon crystallites $^{6}$.

\section{3- Creep mechanisms - Primary creep}

Primary creep can be attributed to viscoelastic deformation of carbon at grain boundaries. Viscoelasticity of carbon has been discussed by Kelly ${ }^{20}$ and it has been observed by Sauder et al. $^{21}$ on various carbon fibers at high temperatures. Because of the very weak interaction between layer planes, each basal plane can deform as a separate unit in two dimensions, which produces substantial basal plane $\operatorname{shear}^{20}$. Furthermore, magnitude of viscoelastic response of carbon fibers under tension depends on orientation of graphitic planes ${ }^{21}$. It increases with the fraction of graphitic planes with a large angle to loading direction (isotropic carbon). By contrast, it is limited in the anisotropic fibers, in which most of the graphitic planes are oriented parallel to loading direction. In SiC fibers, orientation of graphitic planes is influenced by grain boundary distribution. Thus, graphitic planes can take all orientations. Furthermore, it was indicated earlier that the carbon present in these SiC fibers consists of 
stacks of a few graphitic planes. As a consequence, primary creep may involve deformation of carbon at grain boundaries and grain sliding due to basal plane shear.

It is worth mentioning that primary creep was more significant in those fibers that contained a large amount of carbon (Hi-Nicalon). This supports the above carbon deformation driven mechanism.

Although Hi-Nicalon and SA3 (1) fibers possessed the same fraction of carbon, Hi-Nicalon fiber showed larger sensitivity to creep. This discrepancy can be attributed to grain size, that is much smaller in Hi-Nicalon fiber. It can also be related to the structure of carbon which displayed a better organization in SA3 (1) fiber (smaller distance between two successive layers : $d_{002}$ ), as a result of higher processing temperature. Low $d_{002}$ implies a larger stiffness and smaller deformations.

Hi-Nicalon fiber contains a significant amount of low density SiC. This SiC phase is not stable, as a result of short duration of pyrolysis step during fiber processing ${ }^{5}$. Grain growth thus starts at $1200^{\circ} \mathrm{C}$ in $\mathrm{Hi}-\mathrm{Nicalon}$ fiber. It causes creep rate decrease. This phenomenon may explain the imperfect fit of experimental creep curve by equations (1) -(4) (figure 6 (a)).

\section{4- Secondary creep : mechanism}

Stationary creep was investigated essentially on Hi-Nicalon S and Tyranno SA3 fibers, which displayed a reasonably short primary creep stage. Extensive investigation of Hi-Nicalon would have required long experiments, as indicated above. 
Creep rate in the steady state is expressed by the following general relationship : $\dot{\varepsilon}=\phi D_{o} d_{g}^{m} \sigma^{n} \exp \left(-\frac{Q}{R T}\right)$

$$
\mathrm{D}=\mathrm{D}_{\mathrm{o}} \exp \left(-\frac{Q}{R T}\right)
$$

Where $\phi$ is a material constant, $\mathrm{D}$ is diffusivity, $\mathrm{Q}$ is the apparent activation energy, $\mathrm{R}$ is the universal gas constant, $\mathrm{T}$ is temperature in Kelvin, $\mathrm{dg}$ is the grain size, $\sigma$ is the applied stress, and $m$ and $n$ are exponents. Different values of $m$ and $n$ correspond to different mechanisms. Values of $\mathrm{n}$ and $\mathrm{Q}$ may be obtained experimentally and used to infer a rate-controlling mechanism for creep.

The creep rate depends on temperature through an Arrhenius exponential term (equation 5). Figure 8 shows typical Arrhenius creep rate plots obtained for the SA3 (2) fiber. Activation energy was determined by fitting equation (5) to creep rates determined at various temperatures.

The largest apparent activation energy was determined for Hi-Nicalon S fibers (table 2). Lower similar values were obtained for both SA3 (1) and SA3 (2) fibers. Knowing that the main difference between both SA3 fibers lies in the amount of free carbon, this result indicates that secondary creep was not influenced by the amount of carbon.

Determination of stress exponent by fitting equations (5) to creep rates determined at different stresses (figure 9), yields stress exponents of 2.5 for all the fibers. It is worth mentioning that plots of strain rates determined under various temperatures and applied stresses (figures 8-10), 
and creep parameters reported in table 2 do not exhibit a noticeable discrepancy, which demonstrates the pertinence of experimental work.

$\mathrm{n}=1$ has been determined for polycrystalline $\mathrm{SiC}$ ceramics. Creep results from diffusional processes either at grain boundaries (Coble creep $n=3$ ) or within grains (Nabarro Herring creep $n=2$ ). High activation energy corresponds to Nabarro Herring creep. Creep rate is very sensitive to grain size (equation 5 ) $: \mathrm{m}=2$ or 3 . Identical trends have been reported for both $\alpha-$ and $\beta-\mathrm{SiC}$.

Diffusional creep in polycrystalline $\mathrm{SiC}$ occurs by diffusion of carbon $^{22}$ or silicon $^{23}$ at grain boundaries $^{22,23}$ or within grains ${ }^{24}$ or by diffusion of impurities at grain boundaries ${ }^{25}$. There is a very limited amount of data on diffusion of carbon and silicon elements in SiC. There is no consensus about diffusion rate. Depending on author, diffusion rate of carbon would be 100 times faster than that of silicium ${ }^{26,27}$, or it would be slower ${ }^{28}$. Activation energies for diffusion of carbon and silicium within grains in $\beta-\mathrm{SiC}$ made via Chemical Vapor Deposition have been estimated to be $840 \mathrm{KJ} \mathrm{mol}^{-1} 29$ and $910 \mathrm{KJ} \mathrm{mol}^{-130}$ respectively. It is worth reminding that creep of polycrystalline $\mathrm{SiC}$ cannot be controlled by dislocation motions at temperatures $<1700^{\circ} \mathrm{C}^{31,32}$. For Nicalon $\mathrm{SiC}$ fibers tested in $\mathrm{CO}, \mathrm{n} \approx 1$. Activation energy was found to be consistent with activation energies of thermally activated viscous flow of glasses at high temperatures ${ }^{33}$.

n exponents between 2 and 3 that have been determined for low oxygen content $\mathrm{SiC}$ fibers ${ }^{34-36}$ correspond to grain boundary sliding in the absence of glassy phase ${ }^{37}$. 
Creep of the fibers of this study $(\mathrm{n} \approx 2.5)$ may be attributed to grain boundary sliding, without grain elongation and glassy phase (Rachinger mechanism). In polycrystalline ceramics, accommodation results from diffusion and fold formation at triple junctions ${ }^{37}$. In SiC fibers, it probably involves carbon deformation.

Apparent activation energy determined on Hi-Nicalon S $\left(770 \mathrm{KJ} \mathrm{mol}^{-1}\right.$, table 2$)$ is consistent with that corresponding to diffusion of carbon or silicon within grains ${ }^{28-30}$. Diffusion within grains can be related to feature of microstructure. As it was mentioned in section 2.3.1, grain boundaries were not clearly defined. It may be thought that they cannot be preferred ways for diffusion.

Activation energy determined for SA3 fibers (table 2) is close to that corresponding to diffusion of $\mathrm{Al}$ at grain boundaries in polycrystalline $\mathrm{SiC}^{38-40}$. This suggests the contribution of diffusion of $\mathrm{Al}$ at grain boundaries. It is also close to half pf that one corresponding to diffusion of $\mathrm{C}$ or Si within grains for Hi-Nicalon $\mathrm{S}$ (table 2). So the contribution of diffusion of $\mathrm{C}$ or $\mathrm{Si}$ at grain boundaries cannot be discarded.

Figure 10 compares creep rates for Hi-Nicalon S and SA3 (2) fibers under $850 \mathrm{MPa}$. It appears unambiguously that creep deformations are larger in SA3 fibers, despite the presence of bigger grains. This trend can be attributed to the presence of Al. Aluminium is known to favour diffusion at high temperature. This causes an increase in the diffusion coefficient D (equation 5). At temperatures above $1500^{\circ} \mathrm{C}, \mathrm{SA} 3$ fiber becomes more creep resistant than HiNicalon S.

\section{5- Tertiary creep stage}


Figures 7 and 11 clearly indicate that, at very high temperatures, the creep rate accelerates into a tertiary stage. In order to identify the creep mechanism, tests were interrupted during the third stage and cross section of fibers was examined using scanning electron microscopy. Figures 11 and 12 show the typical microstructure of fibers that was observed. It consists of two distinct parts : the core and an annular region. The microstructure of the core was unaffected whereas Auger analysis showed that the annular region was made of pure carbon. Furthermore, the diameter of fiber was unchanged. These results suggest that silicon volatilized and that this phenomenon advanced from the surface towards the core. Data in the literature support this assumption. Thus, figure 13 shows that $\mathrm{SiC}$ decomposes at temperatures above $1400^{\circ} \mathrm{C}$ when pressure is identical to that one in the chamber $\left(10^{-4} \mathrm{~Pa}\right)$. Furthermore, authors have shown that gaseous $\mathrm{Si}(\mathrm{g})$ is produced preponderantly under these conditions ${ }^{41-}$ 48. Experimental conditions were favourable to silicon volatilization. Thermodynamic equilibrium could not be reached and pressure of gaseous $\mathrm{Si}(\mathrm{g})$ remained above equilibrium value in the chamber :

i) pressure in the chamber $\left(10^{-4} \mathrm{~Pa}\right)$ is smaller than that of $\mathrm{Si}(\mathrm{g})$ at temperatures above $1400^{\circ} \mathrm{C}$, according to figure 13 . As a consequence, gaseous species can be eliminated.

ii) Chamber wall was covered with a deposit after the tests, indicating that gaseous products condensed.

The above phenomenon cannot be attributed to active oxidation from residual oxygen. Active oxidation would have a more serious effect. Under such vacuum conditions, oxidation products $(\mathrm{SiO}(\mathrm{g})$ and $\mathrm{CO}(\mathrm{g}))$ would be continuously eliminated, so that the fiber would be completely destroyed. Authors who observed degradation of SiC fibers at high temperature 


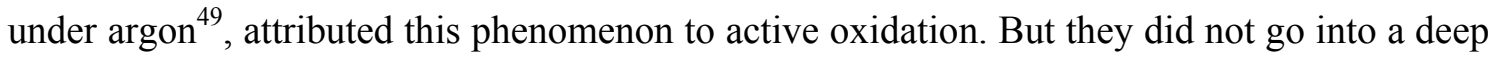
investigation to ascertain their interpretation.

The creep rate acceleration would result from a change in the stress state in the $\mathrm{SiC}$ fiber, caused by the annular degradation of fiber. During Si volatilization, stiff $\mathrm{SiC}$ is replaced by a porous carbon material that is much more compliant. As a consequence, the load is carried preponderantly by the $\mathrm{SiC}$ core. As annular degradation proceeds, there is an increase in stress, according to the following equation :

$$
\sigma(\mathrm{t})=\frac{\sigma_{o} R_{c}^{2}}{\left(R_{c}-e(t)\right)^{2}}
$$

where $\sigma_{o}$ is the applied stress, $R_{c}$ is the fiber diameter and $e(t)$ is the thickness of annular carbon layer.

In a first step, a simple linear time dependence was selected for $\mathrm{e}(\mathrm{t})$ :

$$
e(t)=k t
$$

The degradation rate was estimated from the thickness of annular layer determined from micrographs of fibers after interrupted creep tests. $\mathrm{K}=2.10^{-12} \mathrm{~m} \cdot \mathrm{s}^{-1}$ was estimated for the HiNicalon S fiber.

Stress relation (6) was introduced into equations (3) and (4). Figure 14 shows the creep curve that was predicted for Hi-Nicalon S. A good agreement with experimental results was obtained, which supports the analysis. Nevertheless, a slight discrepancy can be noticed, 
which may result from approximations in annular degradation law and in load sharing. Contribution of annular carbon layer was neglected. Refinement, if necessary, would introduce a more complex annular degradation law and contribution of carbon layer in load sharing.

\section{6- TEM analysis of crept fibers}

TEM analysis was performed on SA3 (2) fibers tested at $1600^{\circ} \mathrm{C}$ and Hi-Nicalon S fibers tested at $1500^{\circ} \mathrm{C}$. Creep tests were interrupted when total deformation of fiber reached $6 \%$. The following features were observed :

(i) carbon was highly preponderant in the superficial region (thickness was close to $500 \mathrm{~nm})$

(ii) cavities were not detected at triple junctions. As indicated above it may be thought that accommodation is made possible because of carbon anisotropy

(iii) in Hi-Nicalon S fibers (core), grains were larger when compared with as-received fibers (figure 15)

(iv) in SA3 fibers (core), grains were smaller when compared with as-received fibers (figure 15).

Grain growth in Hi-Nicalon S fibers after treatment at $1400^{\circ} \mathrm{C}$ has been reported in the literature $^{50}$. This phenomenon may be similar to that observed on Hi-Nicalon fibers. It suggests that the finishing treatment aimed at the elimination of carbon was not carried out at a sufficiently high temperature. Grain shrinkage in SA3 fibers is intriguing. It seems logical to look for a connection with Si volatilization. Further investigation is required. 


\section{4- Conclusion}

The tensile creep behaviour of $\mathrm{SiC}$ fibers with a low oxygen content was investigated up to very high temperatures. Tests of long duration were carried out on a high performance testing device. The three stages of creep were evidenced.

Primary creep was particularly long in the Hi-Nicalon fibers. It lasted more than 144 hours. Primary creep was attributed to viscoelastic deformation of carbon at grain boundaries. Primary creep is enhanced by the amount of free carbon. Hi-Nicalon fiber experienced much larger deformations than Hi-Nicalon S and SA3 fibers. Furthermore, shorter primary creep stage was observed on both latter fibers.

Determination of creep constants including stress exponent $(\mathrm{n} \approx 2.5)$ and apparent activation energy suggests the following mechanisms of secondary creep :

- grain boundary sliding without grain elongation and glassy phases (Rachinger type). Accommodation was due to compliance of carbon.

- Diffusion of Al, C or Si at grain boundaries in SA3 fiber

- Diffusion of carbon or silicium within grain in Hi-Nicalon S fiber.

But diffusion of impurities was not established, due to the paucity of data in the literature on diffusion of impurities within $\mathrm{SiC}$ polycrystals.

Tertiary creep was shown to be due to an increase in stress as the load bearing fiber area is reduced by volatilization of Si. Some microstructural changes were detected by TEM analysis such as grain growth in Hi-Nicalon S fibers and grain shrinkage in SA3 fibers. The former can 
be related to some extent to that one observed on Hi-Nicalon fiber, whereas the latter may be associated to Si volatilization.

\section{Acknowledgements}

This work was supported by CNRS and CEA and was accomplished as part of the CPR ISMIR research program. The authors would like to thank J.M. Goyheneche, X. Bourrat and B. Marini (CEA) for valuable discussions. They are grateful to Dr. T. Ishikawa for the support of Tyranno SA3 samples and Nippon Carbon for the supply of Hi-Nicalon S fiber.

\section{References}

${ }^{1}$ T. Muroga, M. Gasparotto and S. J. Zinkle, "Overwiew of materials research for fusion reactors", Fusion Engineering and Design, 61-62 13-25 (2002).

${ }^{2}$ A. Hasegawa, A. Kohyama, R. H. Jones , L. L. Snead, B. Riccardi and P.Fenici, "Critical issues and current status of $\mathrm{SiC} / \mathrm{SiC}$ composites for fusion", Journal of Nuclear Materials, 283-287 128-137 (2000).

${ }^{3}$ H. M. Yun, J. C. Goldsby and J. A. DiCarlo, "Tensile creep and stress-rupture behavior of polymer derived SiC fibers", Advances in Ceramic-Matrix Composites II, 17-28 (1995).

${ }^{4}$ H. M. Yun and J. A. DiCarlo "Comparison of the tensile, creep, and rupture strength properties of stoichiometric SiC fibers", report NASA/TM-1999-209284 (1999).

${ }^{5}$ N. Hochet, M. H. Berger and A. R. Bunsell, "Microstructural evolution of the latest generation of small diameter siC based fibres tested at high temperature", J. Microscopy, 185 243-258 (1997).

${ }^{6}$ R. Bodet, X. Bourrat, J. Lamon and R. Naslain, "Tensile creep behavior of a silicon carbidebased fiber with a low oxygen content", J. Mat. Sci., 30 661-677 (1995). 
${ }^{7}$ G. Chollon, R. Pailler, R. Naslain and P. Olry, "Correlation between microstructure and mechanical behaviour at high temperatures of a SIC fibre with a low oxygen content (HiNicalon)", Journal of Materials Science, 32 1133-1147 (1997).

${ }^{8}$ J. A. DiCarlo and H. M. Yun., "Microstructural factors affecting creep-rupture failure of ceramic fibers and composites", pp. 119-134 in Ceramic Material systems with Composite structures (1998).

${ }^{9}$ F. A. Kandil and B. F. Dyson, "Tensile creep of ceramics: the development of a testing facility", pp. 151 in mechanical testing of engineering ceramics at high temperatures, ed. B. F. Dyson, R.D. Lohr \& R. Morell. Elsevier Applied Science, London (1989).

${ }^{10}$ I. J. Davies, "Effect of variable radius on the initial creep rate of ceramic fibres", J. Mat. Sci, 40 [23] 6187-6193 (2005).

${ }^{11}$ G. A. Newsome, "The effect of neutron irradiation on silicon carbide fibers", Ceramic Engineering \& Science Proceedings, 18 [3] (1997).

${ }^{12}$ M. H. Berger and A. R. Bunsell, "Thin Foil preparation of small diameter ceramic or glass fibres for observation by transmission electron microscopy", Journal of Materials Science Letters, 12 825-828 (1993).

${ }^{13}$ C. Sauder, J. Lamon, R. Pailler, "Thermomechanical properties of carbon fibers at high temperatures (up to $2000^{\circ} \mathrm{C}$ )”, Composites Science and Technology, 62 [4] 499-504 (2002).

${ }^{14}$ T. Shimoo, H. Takeuchi and K. Okamura, "Thermal stability of Polycarbosilane-derived silicon carbide fibers under reduced pressures", J. Am. Ceram. Soc., 84 [3] 566-570 (2001).

${ }^{15}$ Advanced technical ceramics - Ceramic Composites. Methods of tests for reinforcement Part 6 : Determination of tensile properties of filament at high temperature - European standard CENTC 184, ENV1007-6, 2001. 
${ }^{16}$ S. M. Dong, G. Chollon, C. Labrugere, M. Lahaye, A. Guette, J. L. Bruneel, M. Couzi, R. Naslain and D. L. Jiang, "Characterization of nearly stoichiometric SiC Ceramic fibres", Journal of Materials Science, 36 2371-2381 (2001)

${ }^{17}$ M. H. Berger, N. Hochet and A. R. Bunsell, "Microstructure and thermo-mechanical stability of a low-oxygen Nicalon fibre", Journal of Microscopy, 177 [3] 230-241 (1994).

18 N. Hochet, M. H. Berger and A. R. Bunsell, "Microstructural evolution of the latest generation of small-diameter SiC-based fibres tested at high temperatures", Journal of Microscopy, 185 [2] 243-258 (1997).

${ }^{19}$ T. Ishikawa, T. Sato, Y. Tanaka and M. Suzuki, "A thermally conductive SiC-Polycristalline fiber and its fiber-bounded ceramic", Ceram Eng \& Sci Proceedings, 22 [3] 471-480 (2001).

${ }^{20}$ B. T. Kelly, Physics of graphite, Applied Science Publishers, 1981

${ }^{21}$ C. Sauder, J. Lamon, R. Pailler, "The tensile behavior of carbon fibers at high temperatures up to $2400^{\circ} \mathrm{C}^{\prime \prime}$, Carbon, 42 715-725 (2004).

${ }^{22}$ T.L. Francis and R.L.Coble, "Creep of Polycrystalline silicon carbide", Journal of the American Ceramic Society, 51[2] 115-116 (1968).

${ }^{23}$ Krishnamashari V. and Notis M.R., "Interpretation of high-temperature creep of SiC by deformation mapping techniques", Materials Science and Engineering, 27 83-88 (1977).

${ }^{24}$ Morscher N., Yun H. M. and Goldsby J. C., "Bend stress relaxation and tensile primary creep of a polycrystalline $\alpha$-SiC fiber", pp. 467-478, Plastic deformation of ceramics, edited by R. C. Bradt et al., Plenum Press, New York, 1995.

${ }^{25}$ Grathwohl G., Reets Th. And Thummler F., "Creep of Hot-pressed and sintered SiC with different sintering additives", Science of ceramics, 11 425-431 (1981).

${ }^{26}$ J. D.Hong, M. H. Hon and R. F. Davis, Ceramurgia International, 5[4] 155-160 (1979).

${ }^{27}$ P.Eveno, J. Li, A. M. Huntz And J. Chaumont, "Diffusion of ${ }^{13} \mathrm{C}$ and ${ }^{29} \mathrm{Si}$ implanted ions in SiC", Materials Science and Engineering, B11 [1-4] 331-336 (1992). 
${ }^{28}$ R. N. Ghoshtagore et R. L. Coble, "Self-Diffusion in silicon carbide", Physical Review, 143 [2] 623-626 (1966).

${ }^{29}$ M.H. Hon and R.F. Davis, "Self-diffusion of ${ }^{14} \mathrm{C}$ in Polycristalline $\beta$-SiC", Journal Of Materials Science, 14 2411-2421 (1979).

${ }^{30}$ M.H.Hon, Davis and E. Newbury, "Self-diffusion of ${ }^{30} \mathrm{Si}$ in Polycristalline $\beta$-SiC", Journal Of Materials Science, 15 2073-2080 (1980).

${ }^{31}$ R. Kossowsky, "Cyclic fatigue of Hot-pressed $\mathrm{Si}_{3} \mathrm{~N}_{4}$ ", J. Amer. Ceram. Soc., 56531 (1973).

${ }^{32}$ P.L. Farnsworth and R.L. Coble, "Deformation behavior of dense polycrystalline SiC", Journal of the American Ceramic Society, 49 [5] 264-268 (1966).

${ }^{33}$ R. Bodet, J. Lamon, N. Jia and R.E. Tressler, "Microstructure stability and creep behavior of Si-C-O (nicalon) fibers in carbon monoxide and argon environments", J. Am, Ceram. Soc., 79 [10] 2673-2683 (1996).

${ }^{34}$ H. M. Yun and J. A. DiCarlo, "Comparison of the tensile, creep, and rupture strength properties of stoichiometric SiC fibers", NASA/TM-1999-209284 report, July, 1999.

35 J.A. DiCarlo and H.M. Yun, "Microstructural factors affecting creep-rupture failure of ceramic fibers and composites", Ceramic Material systems with Composite structures, pp. 119-134, 1998.

${ }^{36}$ A. Piant, A. Bunsell et D. Ormston, "Comportement mécanique à haute temperature des fibres SiC de dernière generation", Groupe Français de la Céramique (French ceramic group), Annual meeting 16-18 March 2004 Bordeaux, pp. 81-84, 2004.

37 T.G. Langdon, "Grain Boundary Deformation Process", In Deformation of ceramic materials edited by R.C. Bradt and R.E. Tressler, pp. 101-125, 1974.

${ }^{38}$ Y. O. Tajima and W. D. Kingery, "Grain boundary segregation in aluminium-doped silicon carbide", J. Mater. Sci, 17 2289-2297, 1982. 
${ }^{39}$ J.L. Chermant, F. Osterstock, "Creep Behaviour of SiC-Al Materials", Materials Science and Engineering, 71 147-157, 1985.

${ }^{40}$ K. Schnurer, G. Grathwohl and F. Thummler, Sci. Ceram., 10 645-650, 1980.

${ }^{41} \mathrm{P}$. Rocabois, "Stabilité thermochimique des composites ceramiques base $\mathrm{SiC}$ approche thermodynamique et expérimentale du système Si-O-C-N", Thèse de l'université de Bordeaux $I, 1993$.

${ }^{42} \mathrm{P}$. Grieveson et C. B. Alcock, "The Thermodynamics of Metal Silicides and Silicon Carbide", special Ceramic 1960 (Academic Press, Inc, New York and london) : 183, 1960.

${ }^{43}$ G.V. Samsonov, Plenum press handbooks of high-temperature materials : properties index, N. 2, 1964.

${ }^{44}$ D. L. Hildenbrand et W. F. Hall, "The decomposition Pressure of boron Carbide and the heat of sublimation of Boron", The Journal of Physical Chemistry, 68 [5], 989-993, 1964.

${ }^{45}$ J. E. Sheehan, "Ceramic coatings for carbon materials", Proc. $4^{\text {th }}$ Annual conference “Recent progress into carbon-carbon composites”, pp. 57-98, 1987.

${ }^{46}$ C. B. Alcock, "Zirconium : Physico-Chemical properties of its Compounds and Alloys - I. Thermodynamics properties", Atomic Energy Review - special issue $n^{\circ} 6$ (IAEA - Vienne), pp. 7-63, 1976.

${ }^{47}$ Handbook of Chemistry and Physics, David R. Lide, $71^{\text {st }}$ edition, 1990-1991.

${ }^{48}$ S. C. Singhal, "Thermodynamic analysis of the high-temperature stability of silicon nitride and silicon carbide", Ceramurgia International, 2[3], 1970.

${ }^{49} \mathrm{G}$. Chollon, "Fibres céramiques à base de carbure de silicium et à faible taux d'oxygène", Thèse de l'université de Bordeaux I, 1995

${ }^{50}$ J. J. Sha, T. Nozawa, J. S. Park, Y. Katoh and A. Kohyama, "Effect of heat treatment on the tensile strength and creep resistance of advanced SiC fibers", Journal of Nuclear Materials, 329-333 592-596 (2004). 
Table 1. Properties of SiC fibers investigated in the present study

\begin{tabular}{|c|c|c|c|c|}
\hline \multirow{3}{*}{$\begin{array}{l}\text { Suppliers } \\
\text { Type of fiber } \\
\text { Lot } n^{\circ}\end{array}$} & \multicolumn{2}{|c|}{ Nippon Carbon Co., Japon } & \multicolumn{2}{|c|}{ Ube industries ltd, Japon } \\
\hline & Hi-Nicalon & Hi-Nicalon S & Tyranno SA3 (1) & Tyranno SA3 (2) \\
\hline & 225103 & 320203 & M-0110071 & M-0304041 \\
\hline Diameter $(\mu \mathrm{m})$ & $14^{16}$ & $13^{16}$ & 7.5 & 7.2 \\
\hline Density (g.cm $\left.{ }^{-3}\right)$ & $2.74^{16}$ & $3.0^{16}$ & 3.0 & 3.1 \\
\hline Tensile strength (GPa) & $2.8^{16}$ & $2.5^{16}$ & $2.8^{16}$ & 2.8 \\
\hline Tensile modulus (GPa) & 290 & 375 & 325 & 380 \\
\hline $\begin{array}{l}\text { Grains size (nm) } \\
\text { XRD } \\
\text { TEM }\end{array}$ & $\begin{array}{l}5-10 \\
5-10\end{array}$ & $\begin{array}{l}20 \\
10-50\end{array}$ & $\begin{array}{l}60-70 \\
50-400\end{array}$ & $\begin{array}{l}60-70 \\
50-400\end{array}$ \\
\hline \multicolumn{5}{|l|}{$\begin{array}{l}\text { Chemical composition } \\
\text { (wt./at.\%) }\end{array}$} \\
\hline $\mathbf{S i}$ & $62.1 / 41.3$ & $68.4 / 48.1$ & $\begin{array}{l}66.6 / 46.0 \text { (edge) } \\
60.3 / 39.5 \text { (core) }\end{array}$ & $\begin{array}{l}69.1 / 49 \text { (edge) } \\
66.1 / 45.6 \text { (core) }\end{array}$ \\
\hline $\mathbf{C}$ & $37.7 / 58.5$ & $31.3 / 51.5$ & $\begin{array}{l}\text { 33/53.6 (edge) } \\
39.2 / 60.1 \text { (core) }\end{array}$ & $\begin{array}{l}30.5 / 50.7 \text { (edge) } \\
33.5 / 54.1 \text { (core) }\end{array}$ \\
\hline $\mathbf{O}$ & $0.2 / 0.2$ & $0.3 / 0.3$ & $0.2 / 0.2$ & $0.1 / 0.1$ \\
\hline Al & - & - & $0.3 / 0.2$ & $0.3 / 0.2$ \\
\hline C/Si (at. \%) & 1.41 & 1.07 & $\begin{array}{l}1.16 \text { (edge) } \\
1.52 \text { (core) }\end{array}$ & $\begin{array}{l}1.03 \text { (edge) } \\
1.19 \text { (core) }\end{array}$ \\
\hline
\end{tabular}

Table 2. Steady state creep parameters

\begin{tabular}{lccc}
\hline \multicolumn{1}{c}{ Fibers } & Temperature Range $\left({ }^{\circ} \mathbf{C}\right)$ & $\begin{array}{c}\text { Activation energy } \\
\mathbf{Q}\left(\mathbf{k J . m o l} \mathbf{m}^{-1}\right)\end{array}$ & $\mathbf{n}$ \\
\hline SA3(1) & $1150-1500$ & $370(360-370)$ & $2,5(2,35-2,6)$ \\
SA3(2) & $1150-1500$ & $370(360-370)$ & $2,5(2,3-2,6)$ \\
Hi-Nicalon S & $1300-1500$ & $770(750-770)$ & $2,6(2,4-2,9)$ \\
\end{tabular}




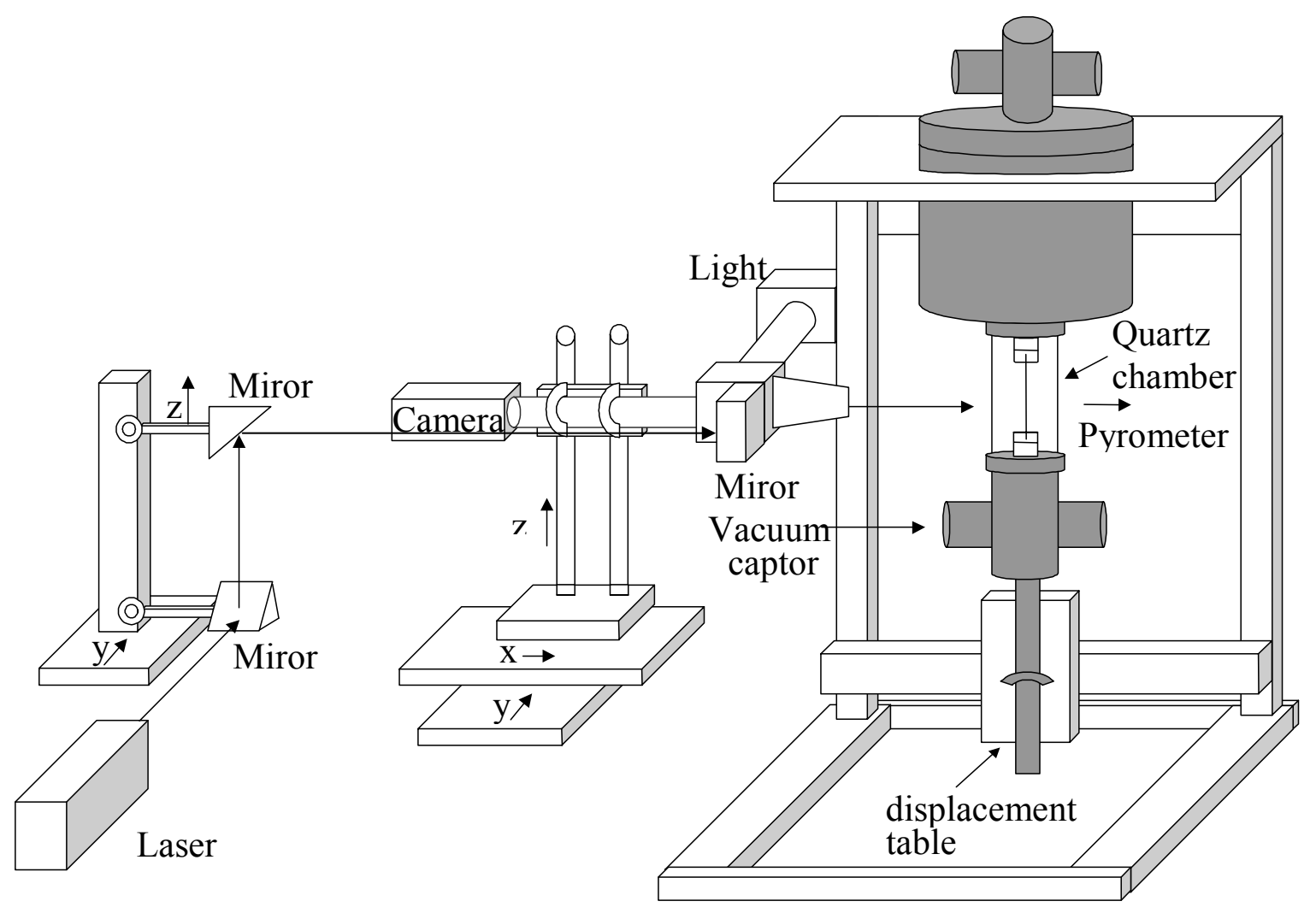

Figure 1: $\quad$ Schematic diagram of the high temperature fibre testing apparatus. 


\section{(a) Hi-Nicalon}

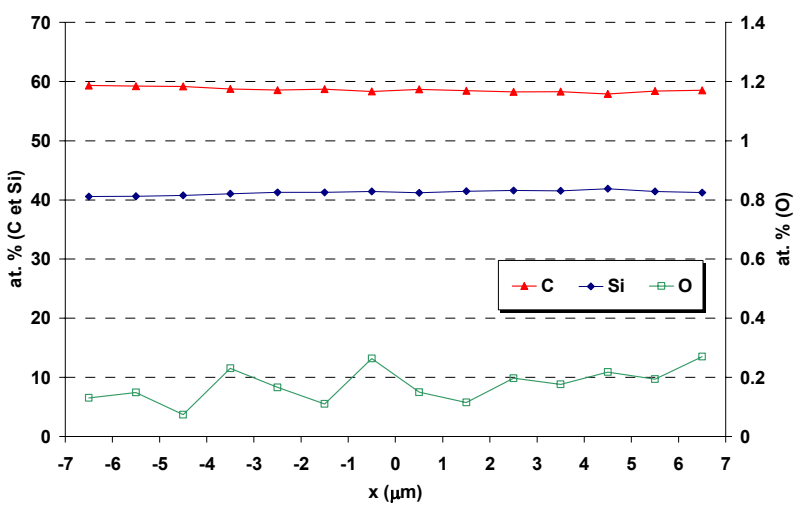

(c) $\mathrm{SA3}(1)$

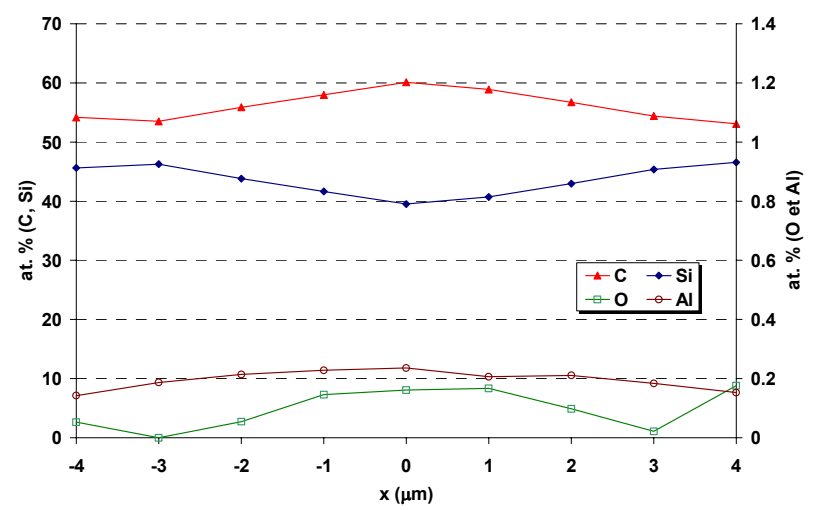

(b) Hi-Nicalon $\mathrm{S}$

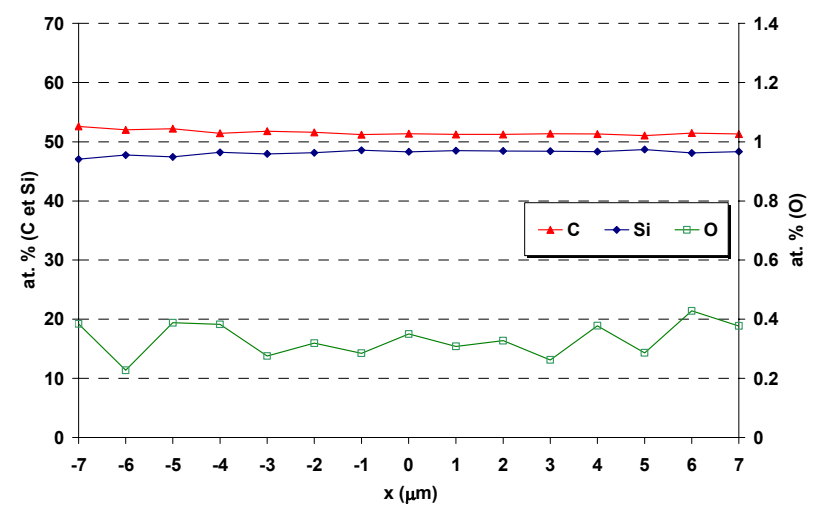

(d) SA3(2)

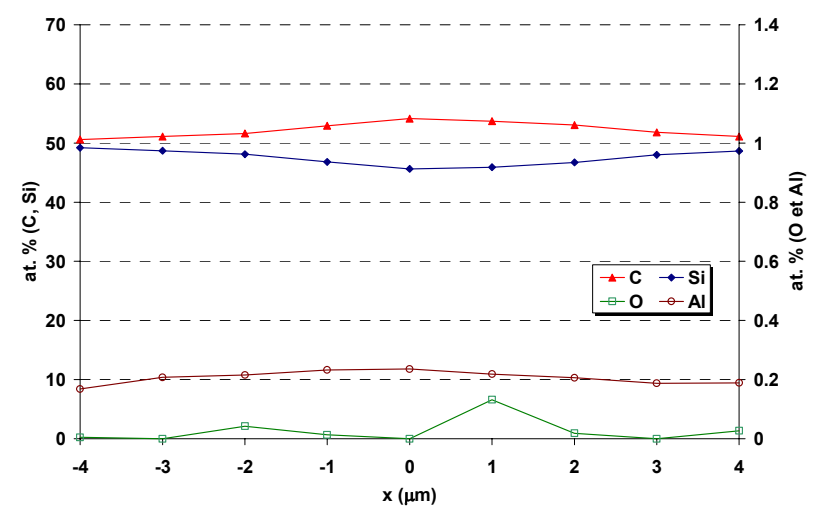

Figure 2: $\quad \mathrm{Si}, \mathrm{C}, \mathrm{O}$ and $\mathrm{Al}$ Atomic concentrations along the diameter of Hi-Nicalon (a), HiNicalon S (b), Tyranno SA3(1) (c) and Tyranno SA3(2) fibre (d) as measured by FРм $\Delta$ 
(a) $\mathrm{SA3}(2)$
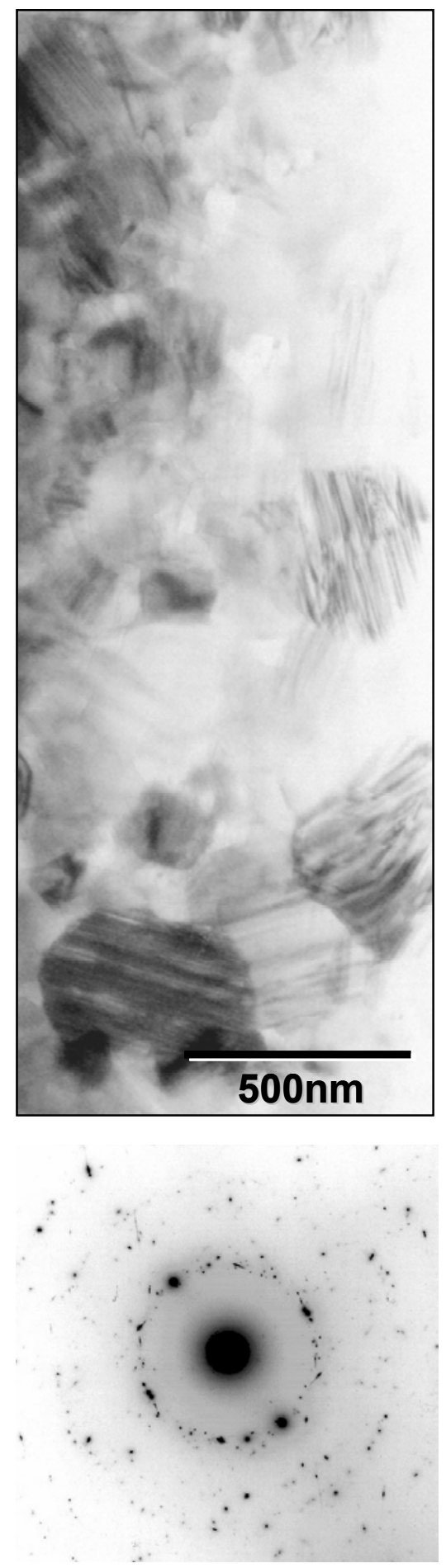

(b) Hi-Nicalon $\mathrm{S}$
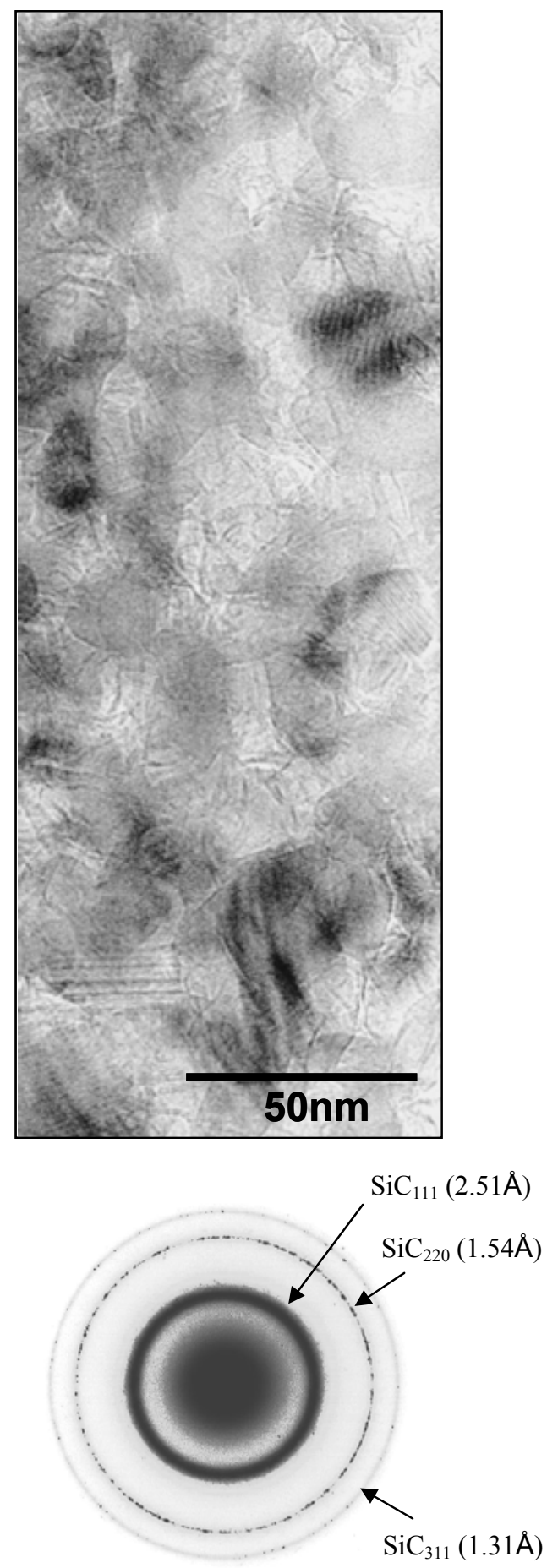

Figure 3: $\quad$ Microstructure and electron diffraction pattern of (a) Tyranno SA3(2) and (b) HiNicalon S fibre. 
(a) Hi-Nicalon $\mathrm{S}$

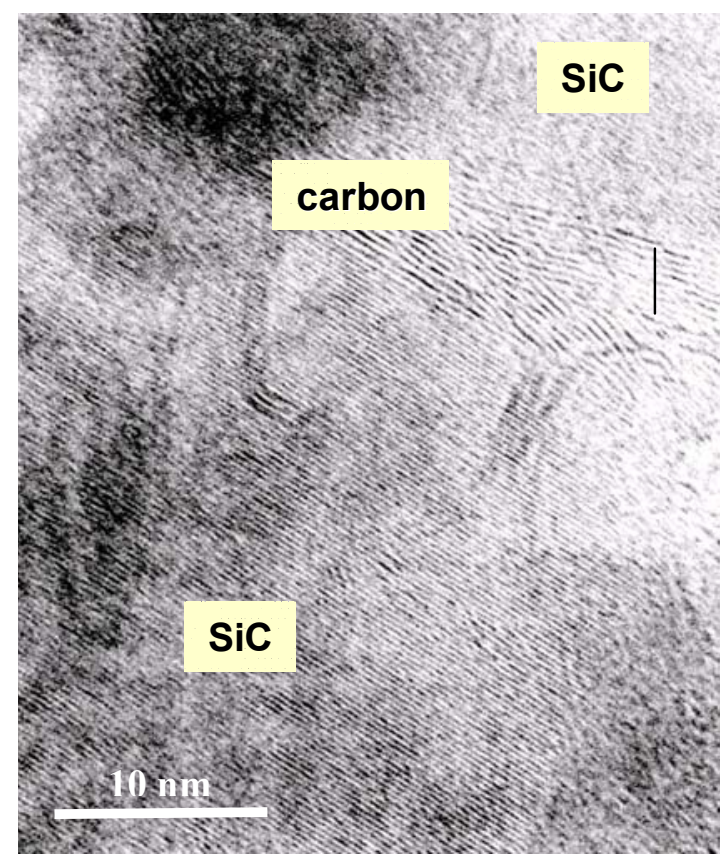

(b) $\mathrm{SA3}(2)$

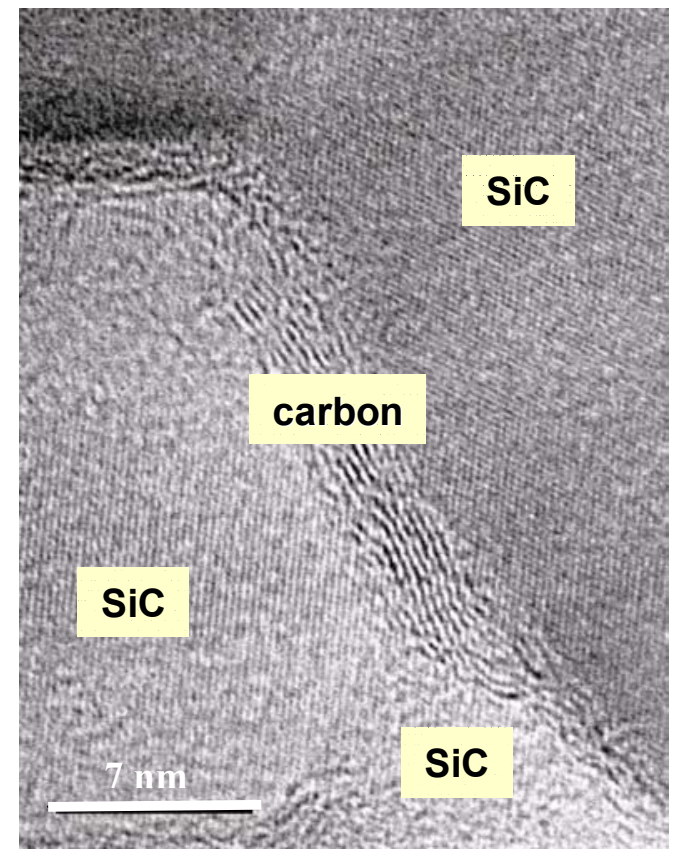

Figure 4: $\quad$ Lattice fringe images showing the presence of turbostratic Carbon at $\mathrm{SiC}$ grain boundary for (a) Hi-Nicalon S and (b) Tyranno SA3(2) fibre. 

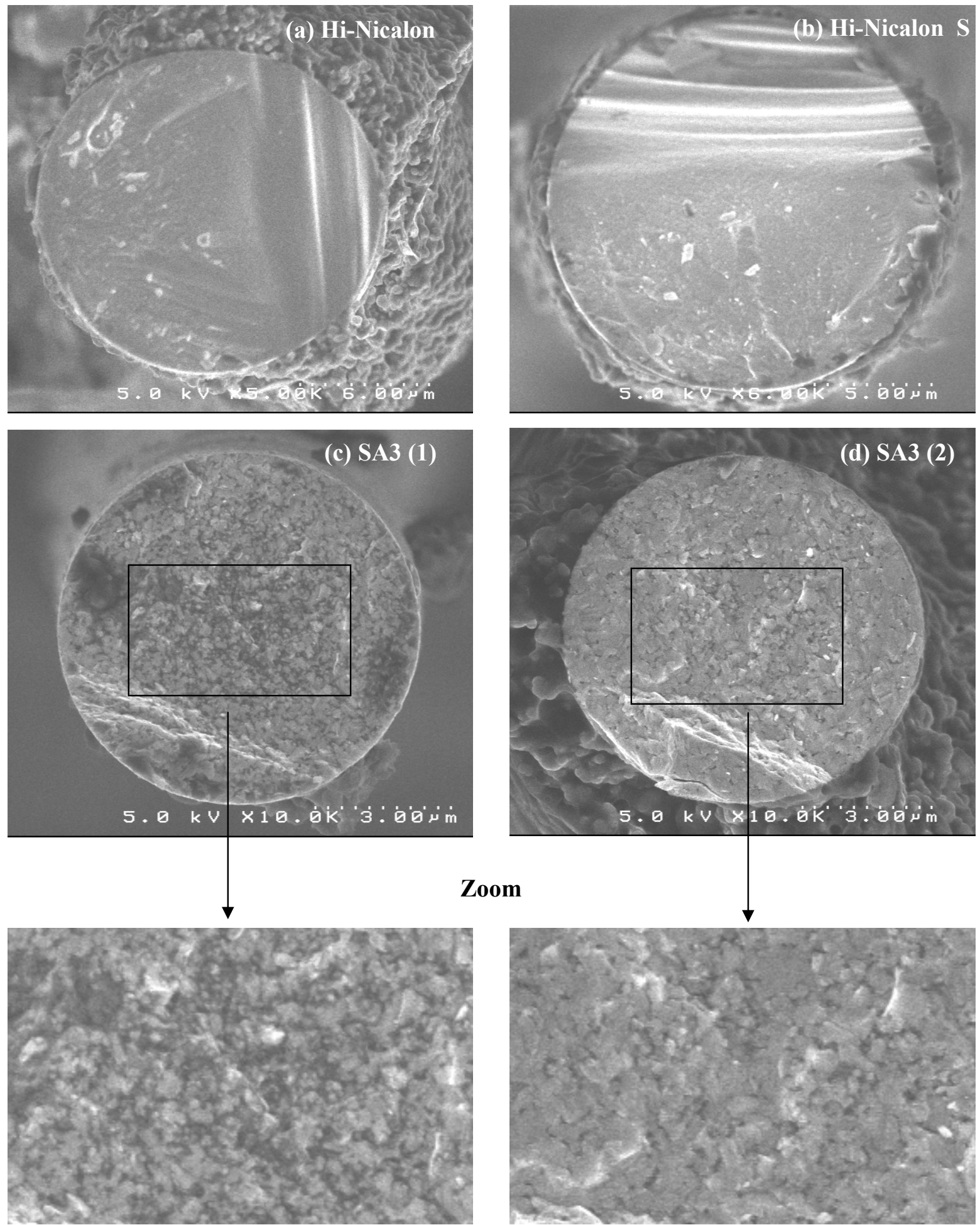

Figure 5: $\quad$ SEM Micrographs of the cross sections of (a) Hi-Nicalon, (b) Hi-Nicalon S, (c) Tyranno SA3(1) and (d) Tyranno SA3(2) fibres. 
(a) Hi-Nicalon

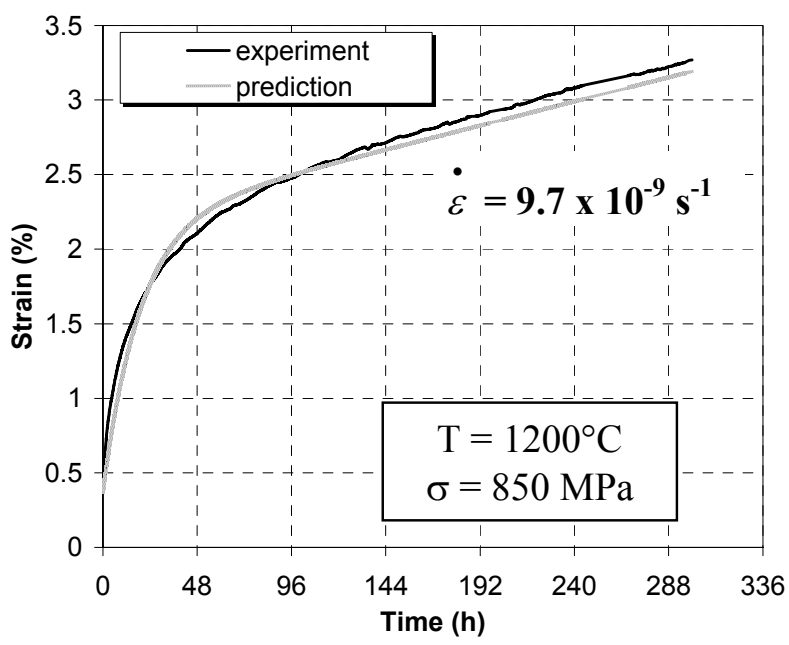

(c) SA3 (2)

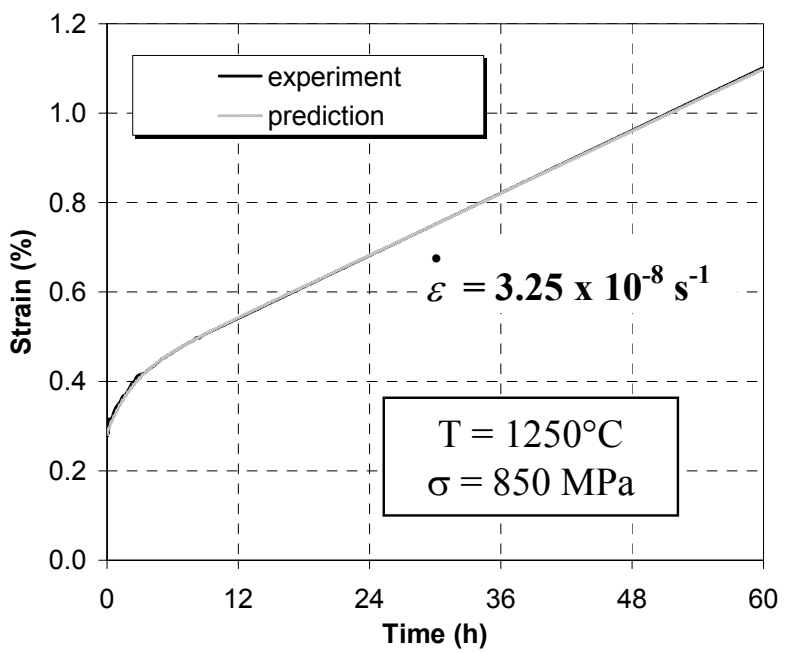

(b) SA3(1)

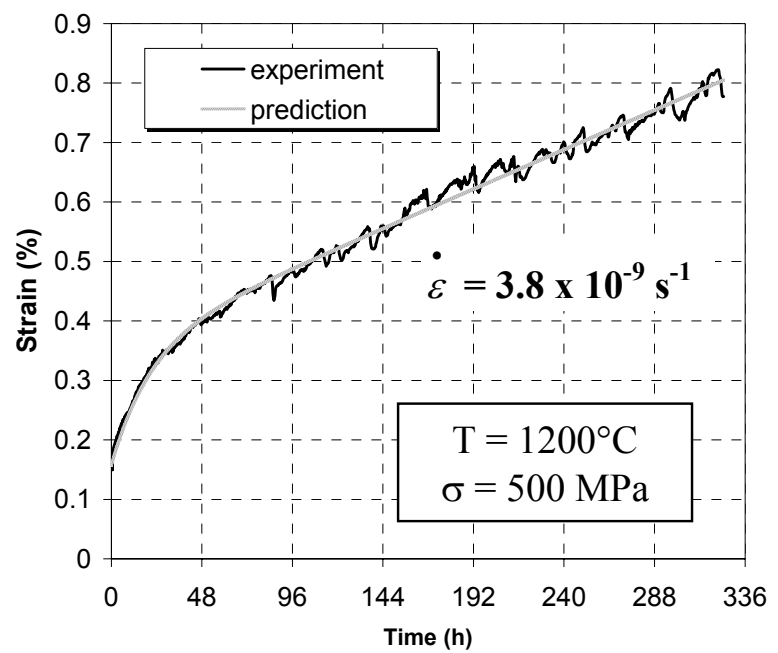

(d) Hi-Nicalon S

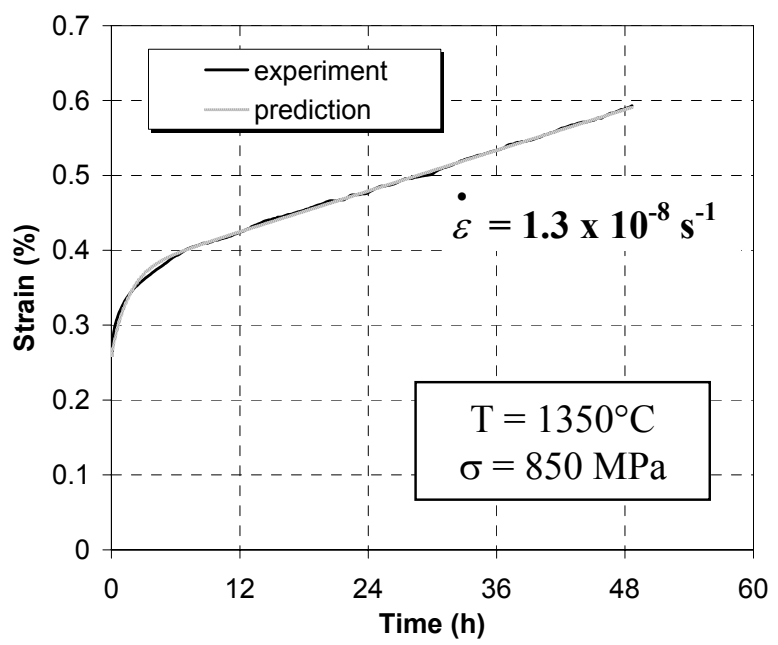

Figure 6: Creep behavior of (a) Hi-Nicalon, (b) Tyranno SA3(1), (c) SA3(2) and (d) HiNicalon S fibers. 


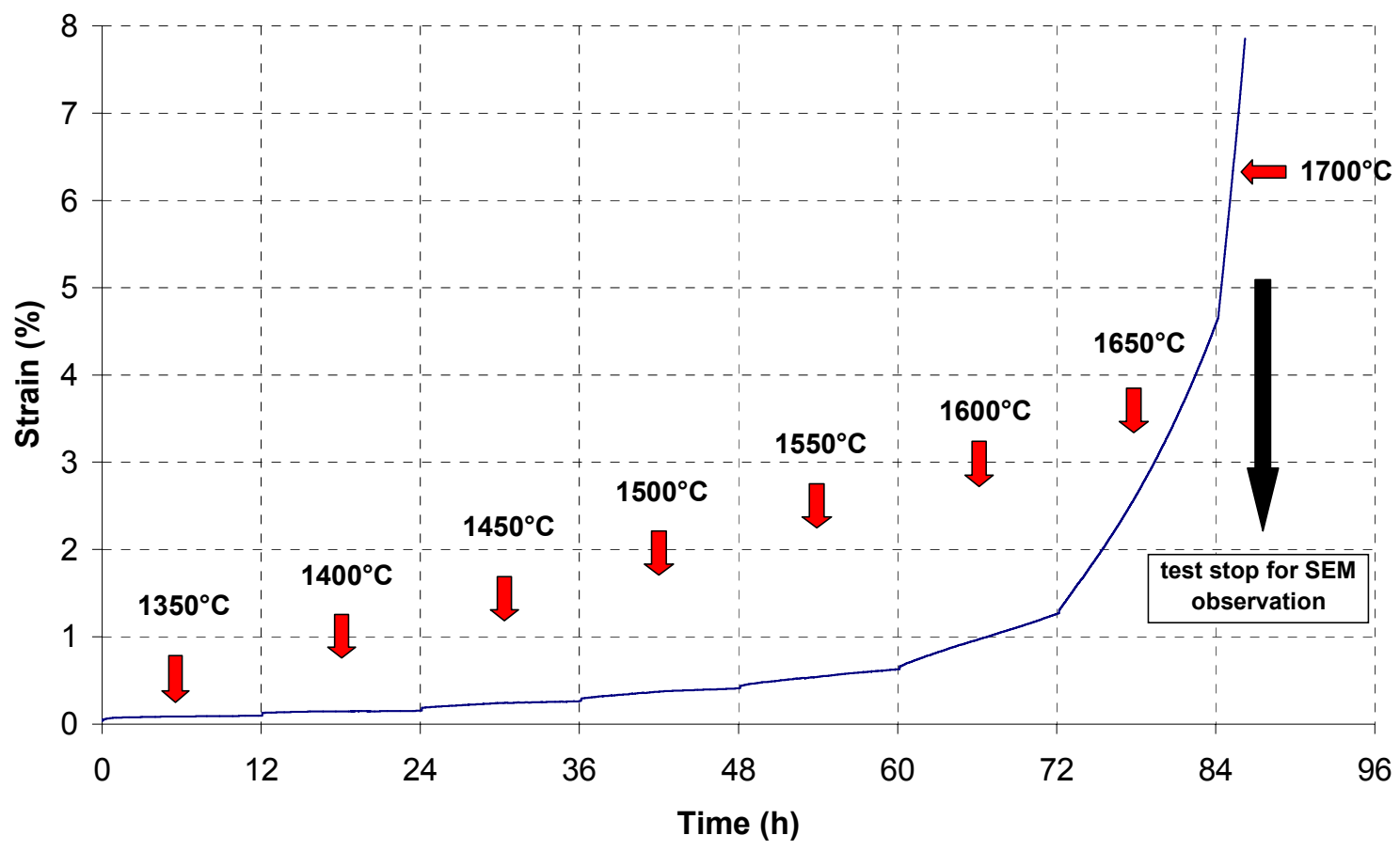

Figure 7: Creep of SA3(2) fiber under a stress of $150 \mathrm{MPa}$ and in the $1350-1700^{\circ} \mathrm{C}$ temperature range.

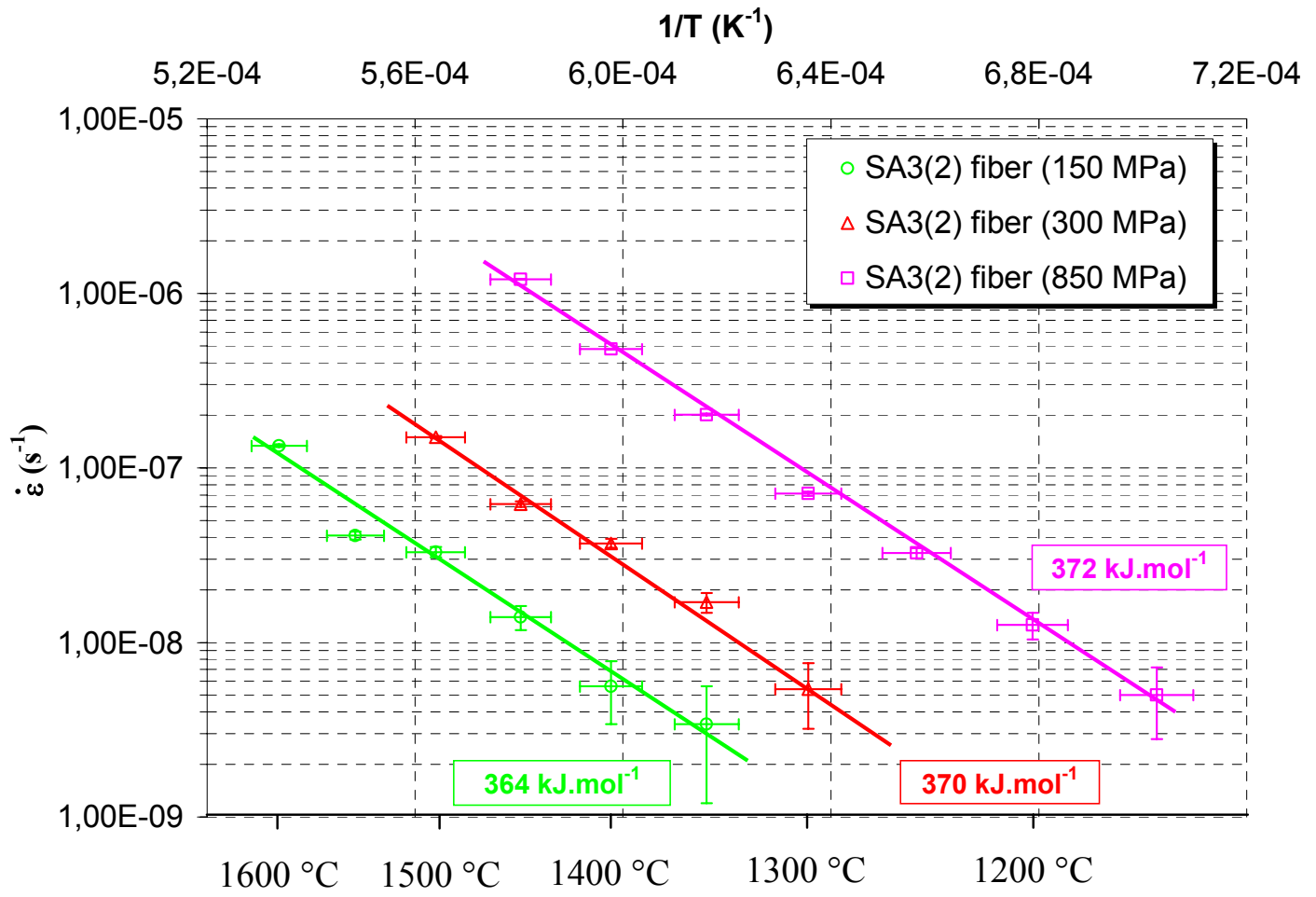

Figure 8: Steady state creep rate versus reciprocal temperature for SA3(2) fiben. 


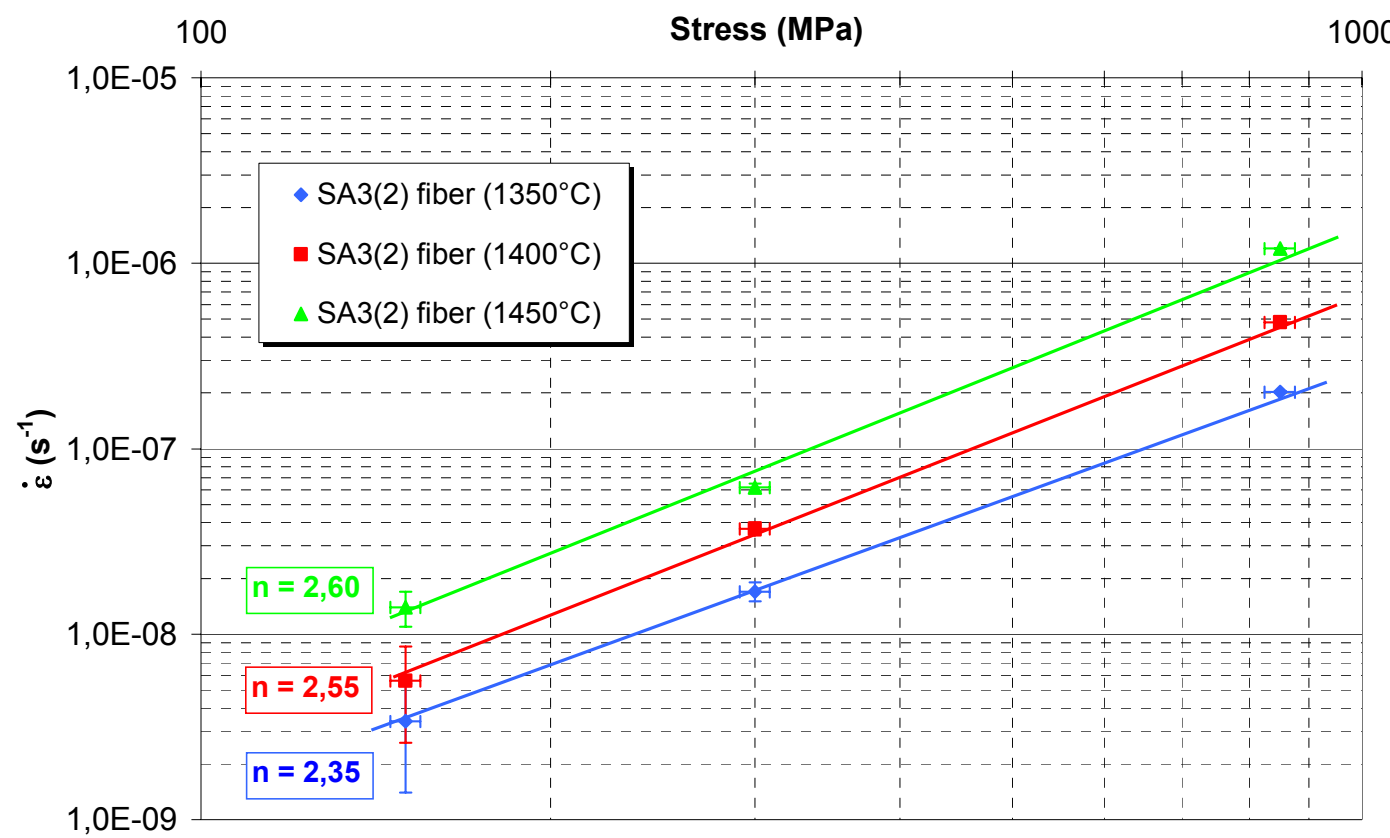

Figure 9: Logarithmic plot of strain rate versus applied stress for SA3 (2) fiber.

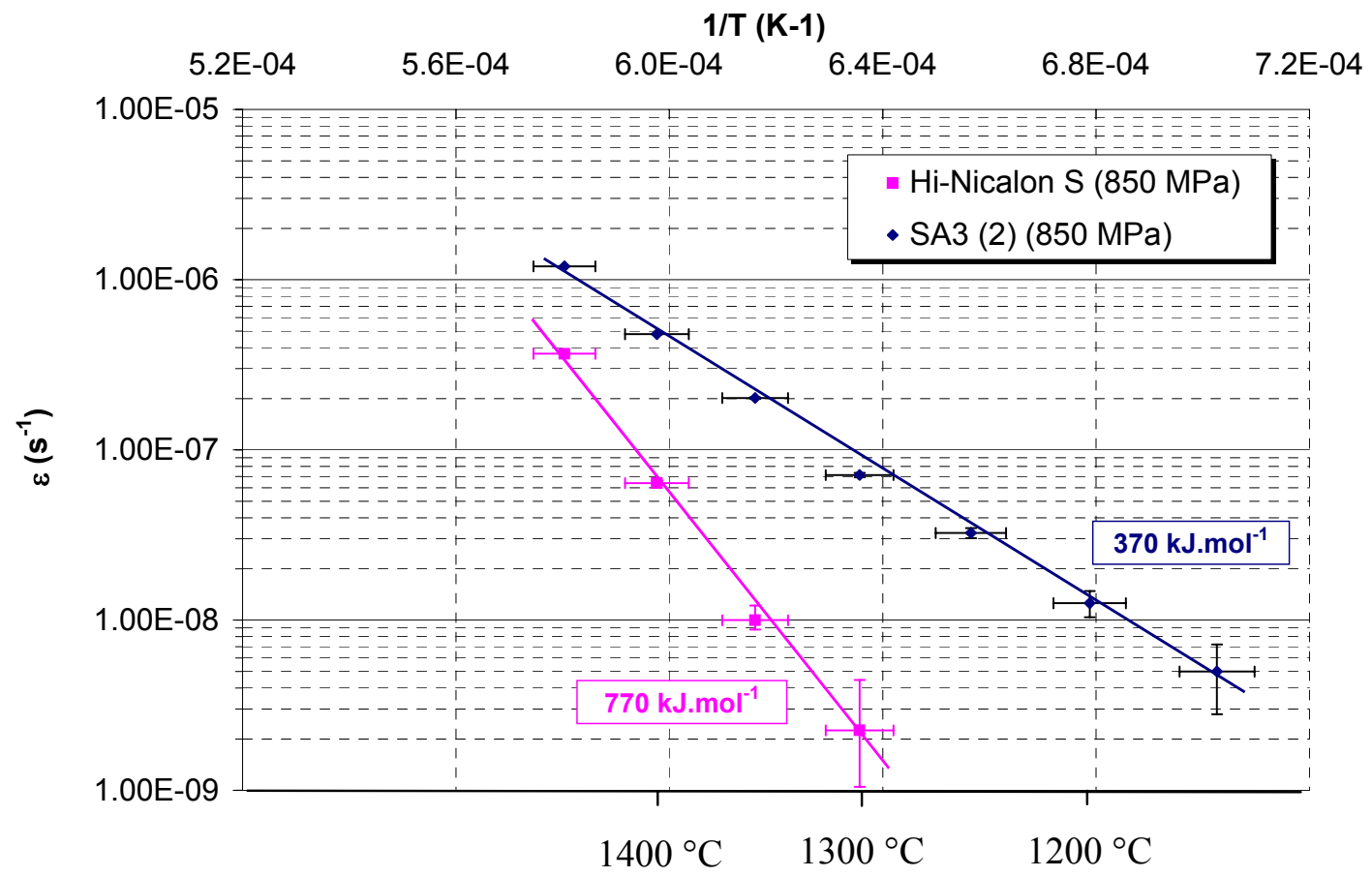

Figure 10: Steady state creep rate versus reciprocal temperature for SA3(2) and Hi-Nicalon $\mathrm{S}$ fibers under a stress of $850 \mathrm{MPa}$. 

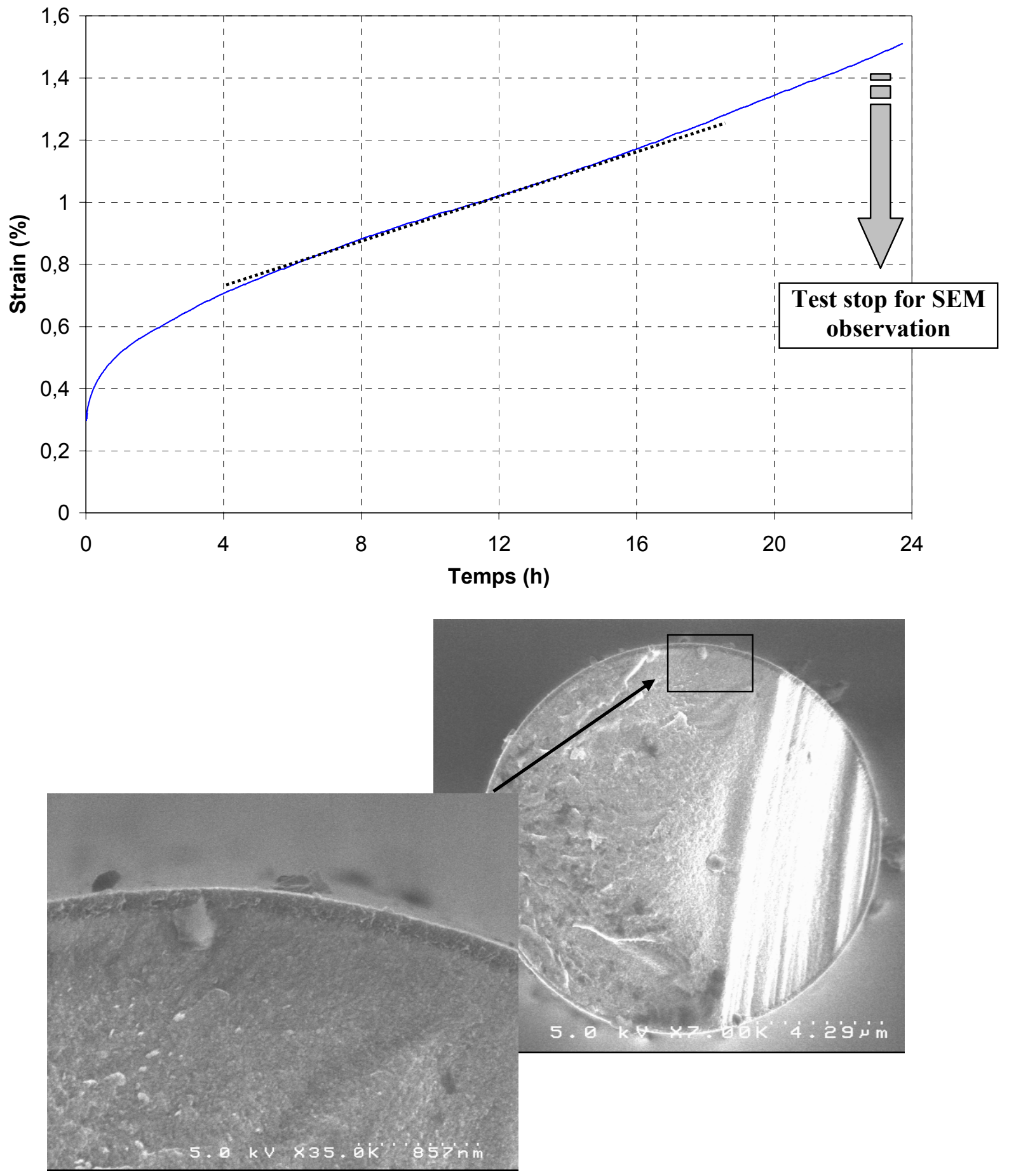

Figure 11: Creep test at $1450^{\circ} \mathrm{C}$ and under a stress of 500MPa for Hi-Nicalon S fiber, and SEM micrographs of cross section after test interruption. 
(a) Global cross section

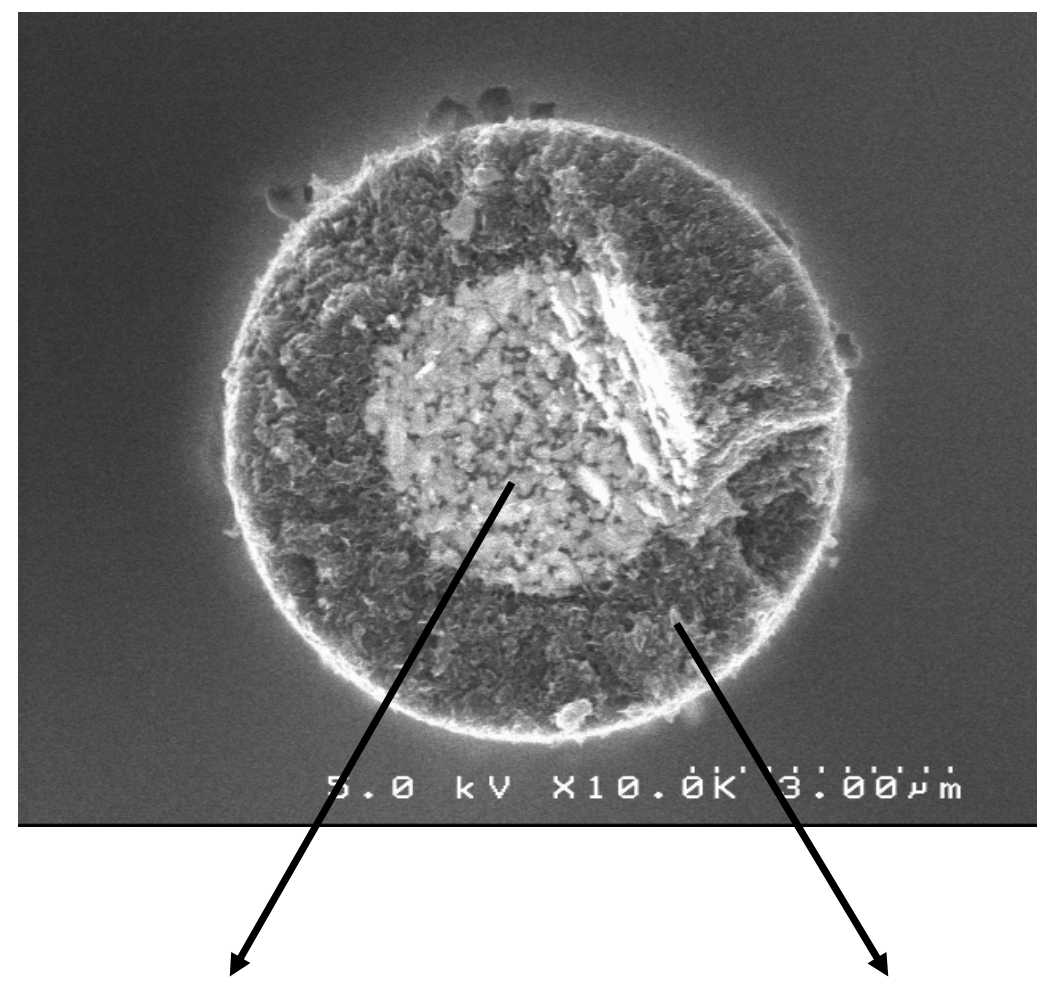

(b) Core observation

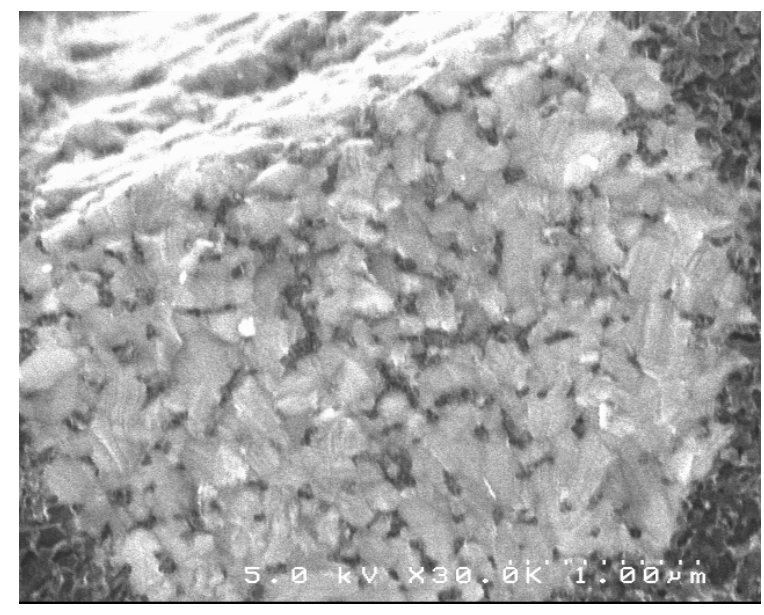

(c) edge observation

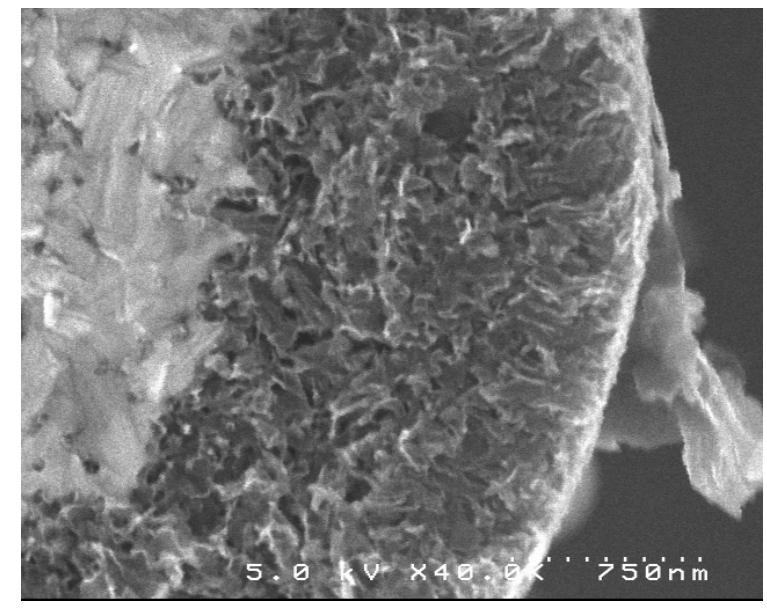

Figure 12: $\quad$ SEM micrographs of SA3(2) cross section after creep test presented of figure 7. 


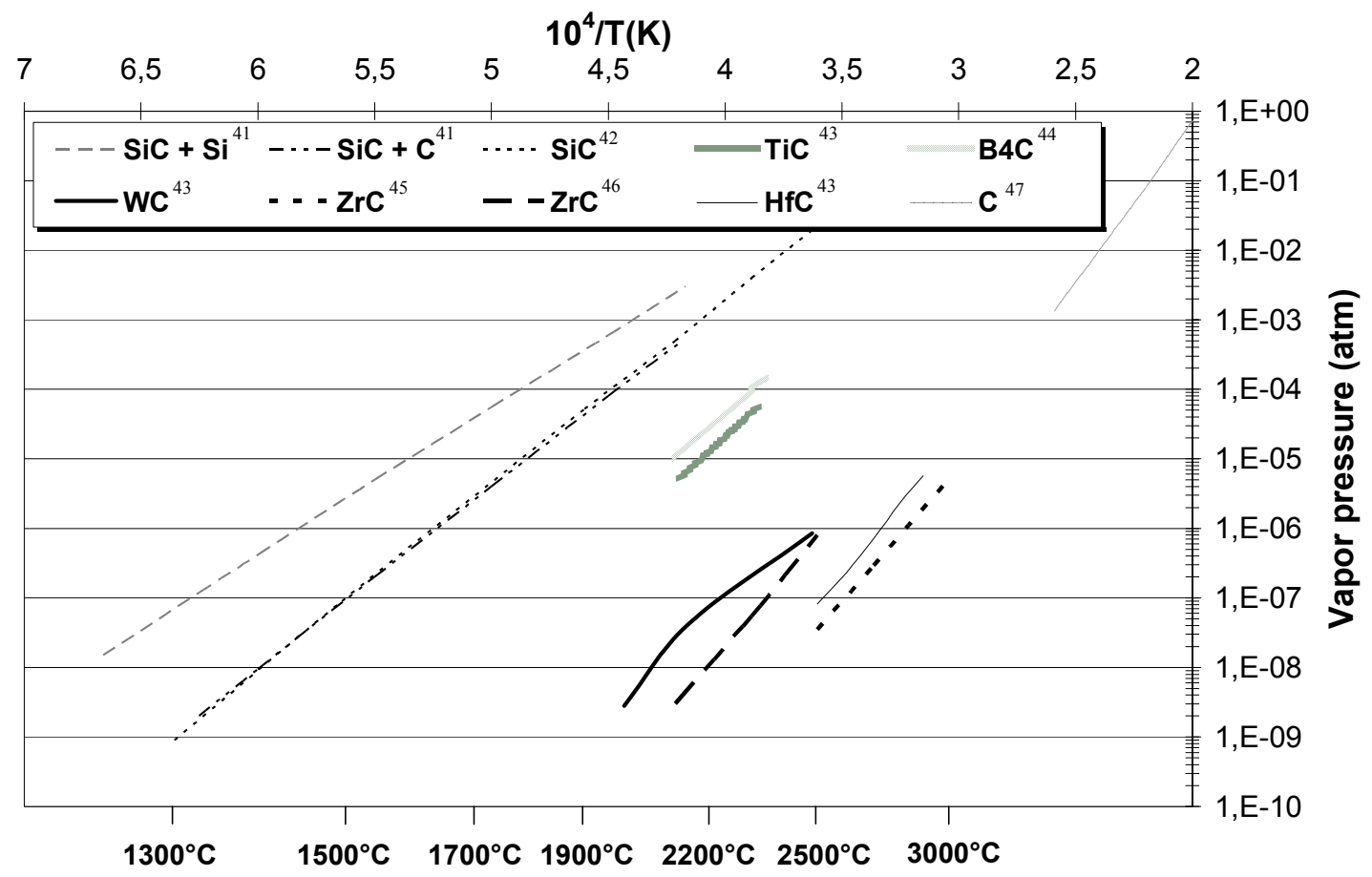

Figure 13: $\quad$ Vapor pressure evolution versus reciprocal temperature for various carbides

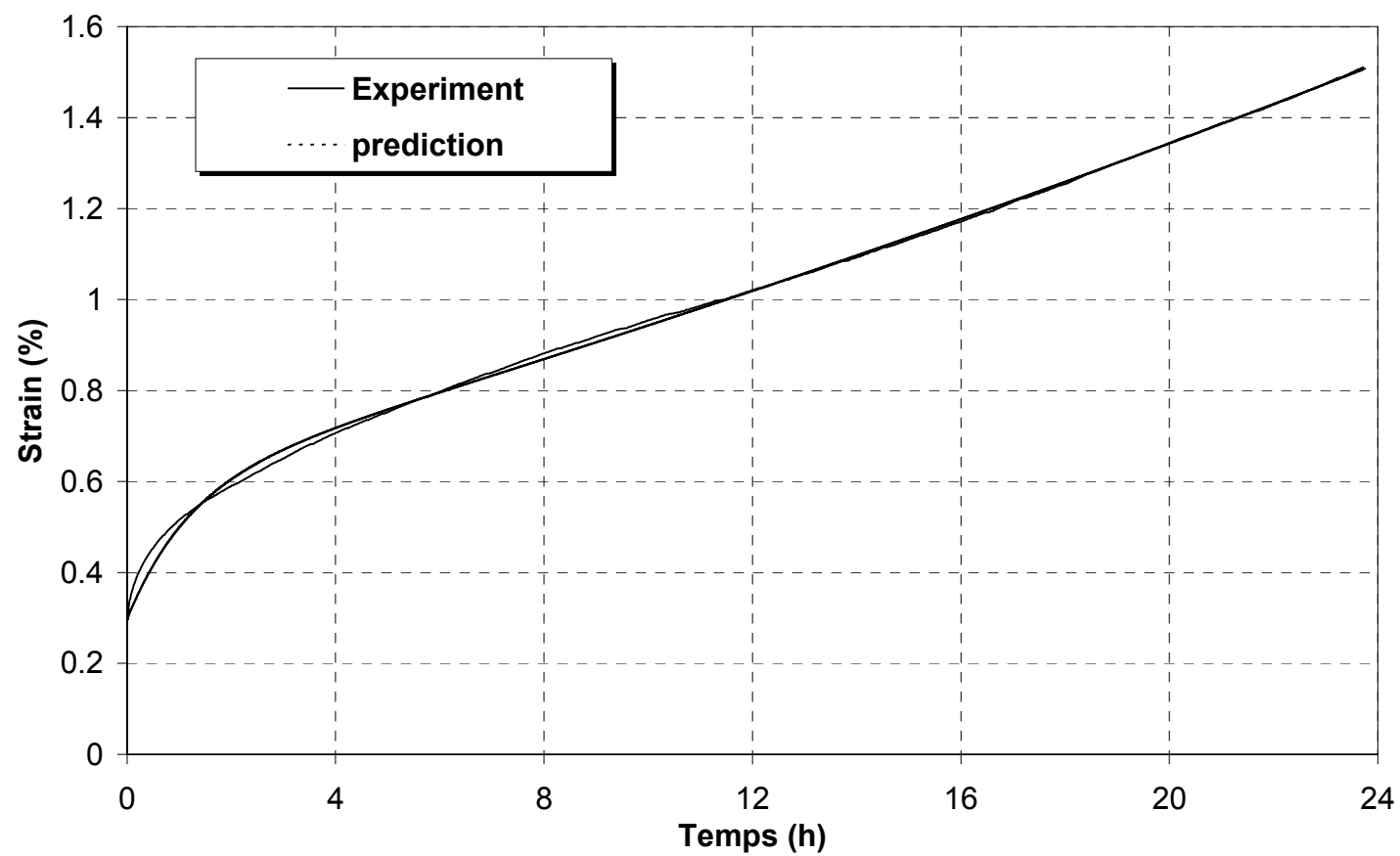

Figure 14: $\quad$ Comparison of experiment and prediction of creep behavior at $1450^{\circ} \mathrm{C}$ and under a stress of 500MPa for Hi-Nicalon S fiber. 
(a) SA3(2)

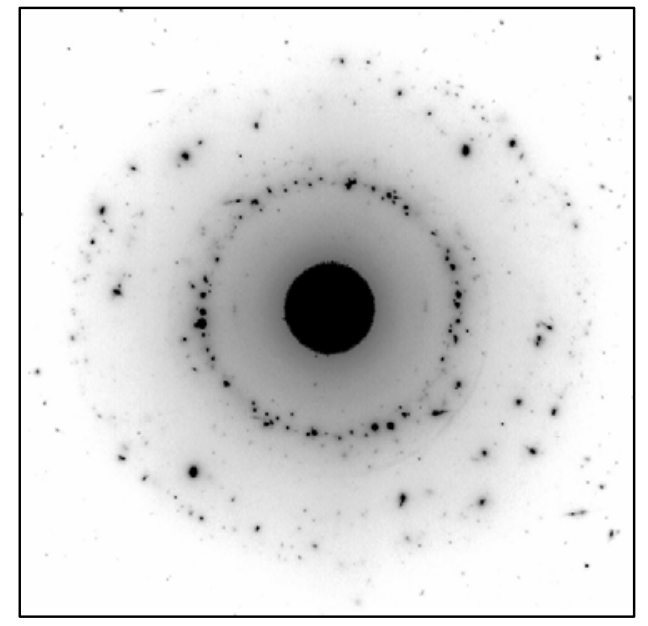

(b) Hi-Nicalon $\mathrm{S}$

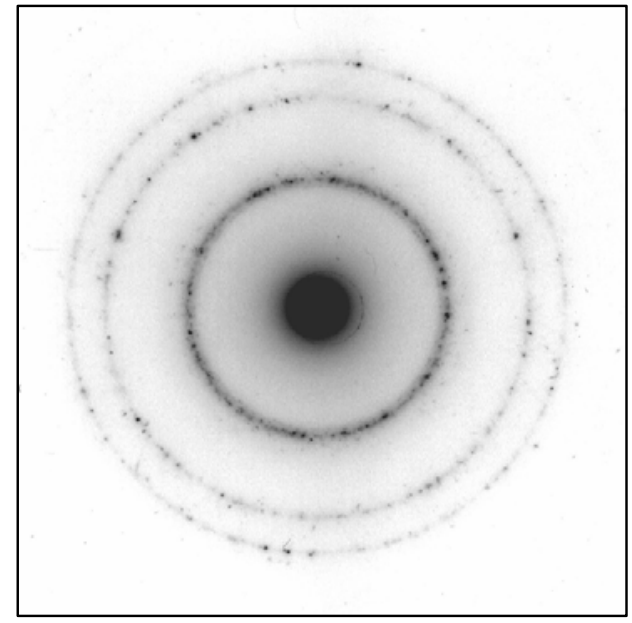

Figure 15: TEM SAD pattern for (a) SA3(2) and (b) Hi-Nicalon $S$ fiber after creep test at high temperature $(\varepsilon=6 \%)$ 